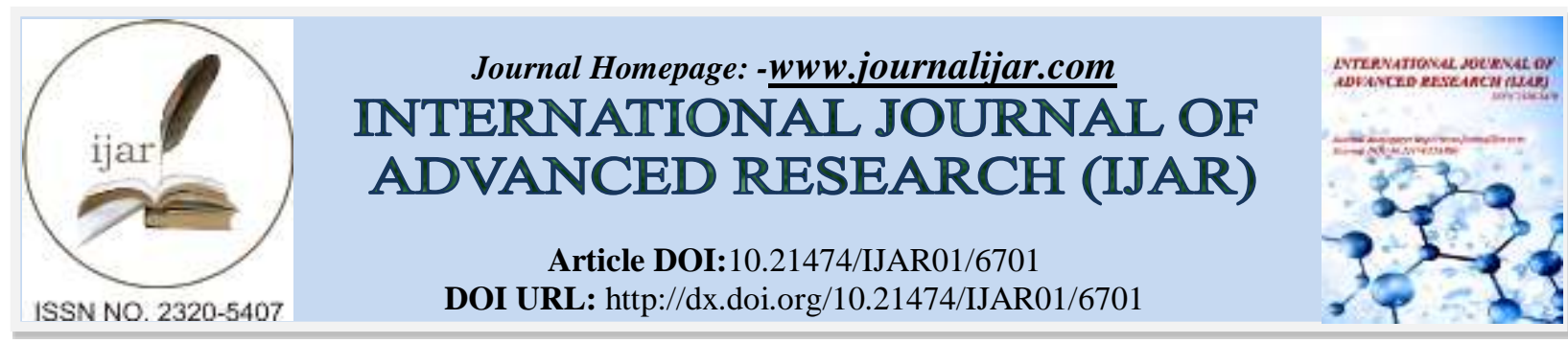

RESEARCH ARTICLE

\title{
ULTRASTRUCTURAL STUDIES OF THE PROVENTRICULUS AND STOMODEAL VALVE OF A TERMITID WORKER (ISOPTERA: TERMITIDAE).
}

\author{
Aziza Darwish and Islam Gabr. \\ Department of Zoology, Faculty of Science, Mansoura University, Mansoura, Egypt.
}

\section{Manuscript Info}

Manuscript History

Received: 08 January 2018

Final Accepted: 10 February 2018

Published: March 2018

Keywords:-

Termite, ultrastructure, proventriculus, stomodeal valve.

\begin{abstract}
The histological structures of the proventriculus and stomodeal valve are investigated by the transmission electron microscope. The wall of the proventriculus is folded forming 48 folds varies in size and thickness of intima. There are 6 primary-, 6 secondary-, 12 tertiary- and 24 quaternary-folds. Each fold formed of a folding layer of epithelial cells and a denticulated intima except the quaternary folds which are spicules in structure, emerged in between each two successive folds. The size of the folds is increased gradually reaching its maximum size at the mid length of the proventriculus then gradually diminished until complete disappearance except the primary folds which dramatically increased in size occupying most of the proventriculus lumen especially at the part of the proventriculus extended into the stomodeal valve. The wall of the valve formed of a fold of the most posterior part of the stomodaeum. The valve is extended into the most anterior part of the mesentron. The epithelial cells of the proventriculus and stomodeal valve are interdigitated at the side resting on the basal lamina and have cytoplasmic processes towards the intima. The nucleus is comparatively large in size occupying the undigitated part. The interdigitated spaces are in direct contact with the haemocoel through the connective tissues and muscle layers.
\end{abstract}

Copy Right, IJAR, 2018,. All rights reserved.

\section{Introduction:-}

The proventriculus is the most posterior part of the stomodaeum (foregut). It is an ectodermal in origin. Its wall commonly formed of - from outside to inside- a thick muscular layer, a continuous single epithelial layer. The epithelium rest externally on basal lamina and internally lined with a cuticular layer known as intima (Gullan and Cranston, 2005; Romoser and Stoffolano, 1998 and Terra et al; 2003).

The thickness of the intima and its degree of sclerotization varies according to the type of food. It is heavily sclerotized with speculated surface in solid feeders as in Gryllus pennsylvanicus and orthopteroid insects (DuPorte, 1918; Judd, 1948). In liquid feeders such as fleas, the intima is modified into directly backward spicules to crush the blood corpuscles taken from its host (Klowden, 2013). In case of female Culex pipiens the intima is denticulated enough to mechanically digest the blood cells before moving into the midgut (Darwish, 2007). The proventriculus of honey bee workers functions of isolation of pollen grains from nectar directing it backwards into midgut while keeping nectar in the crop (Nation, 2016). 
Studies done on proventriculus were on light microscopy level except that of Culex pipiens (Darwish, 2007) which was done by transmission electron microscope. Scanning electron microscope was used to studying the structure of the proventriculus in some insects for example, Gryllus assimilis (Fontanetti and Zefa, 2000), three Endecous spp. of Gryllidae (Fontanetti et al; 2002) and twenty Chinese Tettigoniidae (Orthoptera) species (Wang et al; 2012). The proventriculus of some species of bees was also studied using scanning electron microscope (Serrão, 2001; Serrão, 2005 and Serrão, 2007).

\section{Materials and methods:-}

The worker of the studied termite species were collected from the infested trees nearby the Faculty of Science, Mansoura University main campus, Daqahliyah governorate, Egypt.

The proventriculus was fixed in $2.5 \%$ glutaraldehyde in $0.1 \mathrm{M}$ sodium phosphate buffer (pH7.4) for 2 hours, washed with sodium phosphate buffer and post fixed in 1\% osmium-tetroxide (OsO4) for 2 hours. Dehydration in ascending ethanol series till absolute ethanol which was followed by infiltration with Spurr epoxy resin, sectioning with Leica Ultra cut (UCT) ultra-microtome. Semi-thin sections were stained with toluidine blue $10 \%$ then examined by compound microscope provided with camera Leica ICC50 HD. Ultra-thin sections were stained with uranyl acetate and lead citrate, and then examined by transmission electron microscope JEOL (JEM-1400 TEM) KV 70.

\section{Results:-}

\section{The structure of the proventriculus:-}

\subsection{Light microscopy}

The wall of the most anterior part of the crop (Fig. 1) has shallow folds thrown into the lumen. The folds lined with smooth intima formed of epicuticle, exocuticle and endocuticle. The epithelium of the folds is digitiform. The digitations are facing the muscular layer. The muscles are formed of internal longitudinal patches and external continuous circular layer. This part of crop has a wide lumen. Some folds are formed inclusively of intima, completely devoted of epithelial cells (Fig. 2). It is difficult to differentiate epicuticle from exocuticle as both of them have the same stain density.

As moving backwards the crop, there is a progressive increase in folds length and width (Fig. 3). The intima is differentiated into the distinct three layers. The epicuticle is finely denticulated and has fine spinules. There is a differentiation in stain affinity between exo- and endocuticle. The epithelial layer forming the folds is thicker and less digitated than that do not involved in folds.

At the posterior end of the crop, the epithelial cells in between the folds are interdigitated but inside the folds itself the interdigitation is hardly seen (Fig. 4). Folds of this region of the crop are characterized by lateral side constriction of its intima at the bases of folds emergence (Figs. 4 and 5). The chitinization of the intima is progressively increased with complete disappearance of the spinules (Fig. 5).

The proventriculus is the most posterior part of the fore gut. The anterior region of the proventriculus has numerous folds and wide lumen (Fig. 6). The folds are divided into four types according to its size, so there are six primary, six secondary, twelve tertiary and twenty four quaternary folds (Fig. 6). In this part of the proventriculus, there is a similarity between the primary and secondary folds (Fig. 7). Both of them have narrow basal part, wider middle part and long extended narrow distal part. The epithelial layer is extended into the both types of folds. The interdigitation of the epithelium is hardly seen at light microscopy level. The intima is heavily chitinized at the lateral and basal parts while the chitinization is reduced towards the apex. The only difference between the primary and the secondary fold is the presence of an uppermost non chitinized area in the primary folds (Fig. 7).

The tertiary folds have wide base but they are shorter in length, about one-third of the length of the secondary fold (Fig. 8). Its apical surface is somewhat conical in shape. They are completely formed of thick intima. The intima is differentiated into apical relatively sclerotized part and basal heavily sclerotized one. The epithelial layer is not extended inside this type of folds as none of these folds contains a cavity. As a result the epithelial cells are randomly distributed completely filling the distance between this type of folds and the circular muscle layer (Fig. 8).

The quaternary folds are the most abundant in the anterior part of the proventriculus. In between each two successive folds there is a quaternary fold. They are 24 in number. It has a spine like structure with wide base (Fig. 
8). It is formed of epicuticle and sclerotized exocuticle, the endocuticle is not involved in the spine structure. Each spine carries on its apical part from two to three fine hairs (Fig. 8).

The middle part of the proventriculus is slightly reduced in size comparing to the anterior part. This part is characterized by the narrow lumen (Fig. 9) as a result of the great expansion of the six primary folds, although the noticeable reduction in the size of other types of folds (Fig. 9).

The surface of the apical part of the primary fold is markedly denticulated (Fig. 10). The intima is moderately sclerotized at the basal part while it is unsclerotized at the apical part of this type of folds (Fig. 10). The epithelial cells of the basal part are superficially interdigitated, at the same time it is deeply interdigitated in the side facing the cavity of the apical part of the fold. Striated muscles were extended into the cavity of these folds (Fig. 10).

The size of secondary folds is diminished. The sclerotization of the intima at the basal part is reduced while it becomes unsclerotized at the apical part (Fig. 11). The epithelial cells are superficially interdigitated alongside the fold, the interdigitation facing the fold's cavity and its apical surface facing the intima becomes concave.

The tertiary fold is also reduced in both length and width. The sclerotization of the apical part is generally reduced except the most internal part next to the epithelial layer (Fig. 12). The epithelial cells are gradually enforced into the small cavity of this type of folds and start to form two opposing layers, although the cells are more or less adhered to each other (Fig. 12).

The fate of the quaternary folds which look like a spine with few bristles on its apical end is gradually reduced. These folds are gradually attached to its neighbor folds (Figs. 7 -12) till complete disappearance (Fig. 13).

The proventriculus wideness reduced gradually as moving back towards the cardiac valve (Figs. 5, 9 and 14). The folds diminished in size and reduced in number (fig. 14). There are only five folds extending towards the lumen which becomes narrower. Eleven folds are at different stages of progressive reduction (Fig. 14). The largest fold (Fig. 15) has digitated epithelium, where the nucleus rests in the extending digitated part. In addition, the digitated epithelial cells have cytoplasmic processes facing the endocuticle. The cavity of this kind of folds has oblique striated muscles. The epicuticle is finely denticulated, followed by a thin exocuticle and a quite bulky endocuticle.

At one side of this fold there is another reduced (quite smaller) fold with well chitinized intima and undigitated epithelium. The epithelial cells of the folds successively reduced in size and gradually lose its digitiform and transformed into cubical shape (Figs. $16-18$ ). Cubical epithelium is very obvious in the successive diminished folds (Fig. 19).

The part of the lumen enclosed between each two successive folds is narrow and the dentacles of the folds face each other (Figs. 16 -19). The thickness of the circular muscle layer is successively increased from the anterior to the posterior of the proventriculus (Figs. 6, 9 and 14).

\subsection{Ultrastructure of the proventriculus:-}

\subsubsection{Cuticular layer:-}

The intima which supports the epithelial layer of the proventriculus is highly chitinized. Its thickness varies between the four types of the folds of the proventriculus. It is formed of the usual three layers which are epicuticle, exocuticle and endocuticle. The three parts vary in thickness and sclerotization along the same fold (Fig. 20).

The intima of primary and secondary folds was examined by transmission electron microscope. The intima of both types of folds has the same structures. The intima covers the base of the fold is formed of finely denticulate epicuticle, electron lucent exocuticle and a thin layer of endocuticle. The intima covers the rest of the epithelial cells of the fold is very thick and highly chitinized comparing to that of the basal part. The epicuticle is sclerotized forming short thick spines (Fig. 20). The exocuticle is striated as it is formed of electron lucent layer followed by electron dense one. Both layers are parallel to each other but perpendicular to the epithelial cells of the fold. The endocuticle is formed of electron dense layers alternate with electron lucent ones. The thickness of the endocuticle increased as we move towards the apex of the fold. The electron-dense and lucent layers are parallel to each other and to the epithelial cells of the folds (Fig 21). The endocuticle has numerous electron lucent dots distributing all over the sub layer of this part of the intima. 
Epithelial cells form two thirds of the length of these two types of folds. The rest of the fold is formed of epicuticle and endocuticle but exocuticle is not involved. We can give the name of crown to this part of the fold (Fig. 21). The crown is formed of epicuticle and endocuticle. The epicuticle is heavily chitinized forming spines at quite long intervals. The endocuticle sub layers are oblique in position to the epithelial cells occur at the apex of the fold. The endocuticle of the two sides of the crown meet at the middle region of the crown is mainly electron lucent (Fig. 21).

\subsubsection{Epithelial layer:-}

The epithelial cells are arranged in a single layer. The cells are characterized by having very obvious nucleus with scattered chromatins. The nucleus occupies two thirds of the size of the cell. The apical surface of the epithelial cells facing the intima has numerous short cytoplasmic processes (Fig. 22). The basal part of the cell is resting on the basal lamina. This basal part ramifies forming interdigitated processes. There are intercellular spaces present between the interdigitations and subsequently between the cells (Fig. 22). The intercellular spaces in some regions are dilated and form vacuoles. The spaces are in connection with the haemocoel through the connective and muscular layers (Fig. 22). There are numerous mitochondria in the epithelial cells which are concentrated at the middle part and few at the apical part of the cell (Fig. 23).

The tertiary type of folds is shallow and its epithelium does not folded but the cells are gathered underneath the intima (Fig. 8). Ultra-thin studies revealed tha0t the cells have rounded nuclei surrounded by thin layer of cytoplasm. The cells have interdigitations which form intercellular spaces between them (Fig. 24). The dilations of the spaces are very obvious forming vacuoles of different size. The vacuoles contain electron dense substances. Sometimes the fine vacuoles are connected with the cells itself (Fig. 24). The intercellular spaces are in direct contact with the haemocoel through the connective tissue and muscle layer (Figs. 22 and 25). The epithelial layer is resting on the basal lamina, followed by a layer of connective tissue and a muscular layer (Fig. 25).

\subsubsection{Muscular layer:-}

The muscles which support the proventriculus wall are formed of longitudinal and circular layers. The longitudinal muscles are represented by thin isolated patches but the circular one is a continuous thick layer. Both longitudinal and circular muscles are striated (Fig. 26). The muscles are well represented with its Z lines, sarcomeres, I and A bands, $\mathrm{H}$ zone, thin (actin) and thick (myosin) filaments (Figs. 26- 29). Muscles are uninucleated and the nucleus is elongated (Fig. 27). Each myofibril is ensheathed by sarcoplasmic reticulum (Figs 27 and 28).

Mitochondria are abundant next to the reticulum (Fig. 27 and 28). Myofibrils, T tubules and sarcolemma are well represented in (Fig. 28). The peritoneal membrane encloses the whole alimentary canal and consequently the proventriculus (Figs. 27 and 29).

\section{The structure of the stomodeal valve:-}

The foregut wall extends posteriorly into the most anterior part of the mesentron (midgut). The wall of the foregut then turned upward to encircle the most posterior part of the proventriculus forming the stomodeal valve (Fig. 30).

Histological structure of the part of the proventriculus at the valve region is formed of six folds which more or less have the same size. The folds formed of digitated epithelial cells. The digitation is facing the intima which becomes very thin comparing to that of the rest of the proventriculus. Figure (31) illustrates the valve during constriction state as the lumen enclosed between the folds or that of the center are very narrow. The intima is without any spinules. This part of the proventriculus is still surrounded by continuous muscles layers (Fig. 32). The tracheoles and tracheal cells subsidize this part of the proventriculus (Fig. 32) and the stomodeal valve (Fig. 33).

The muscle layer of the stomodeal valve consists of interrupted patches of circular muscles immersed in thick layer of connective tissue (Fig. 33). The muscle layers of both the proventriculus and the stomodeal valve are facing each other (Fig. 33). The epithelial cells of the foregut fold (stomodeal valve) are greatly interdigitated (Fig. 34). The interdigitations facing the muscle layer of the proventriculus. The nucleus rests in the undivided part of the epithelial cells (Fig. 35).

The intima of the foregut wall (stomodeal valve) is facing the epithelial cell surface of the most anterior part of the mesentron (Figs 35 and 36). The intima of the fore gut of this part is formed of two linear electron dense layers enclosing a narrow electron lucent thin layer and another electron lucent layer. These four layers overly the surface of the epithelial cells (Fig. 36). The epithelial cells of the foregut contain two types of secretory vacuoles. One type 
is electron dense with fine granules mainly concentrated and closely packed at the digitations (Fig. 36). The other type of vacuoles are electron lucent distributed all over the cells and less in number than the previous one (Fig. 36).

The third part of the valve region is the most anterior part of the mesentron. The surface of the epithelial cells is facing the intima of the fore gut. The epithelial cells of the mesentron in this part are arranged in more than one layer, a syncytial layer and cellular layers (Fig. 37).
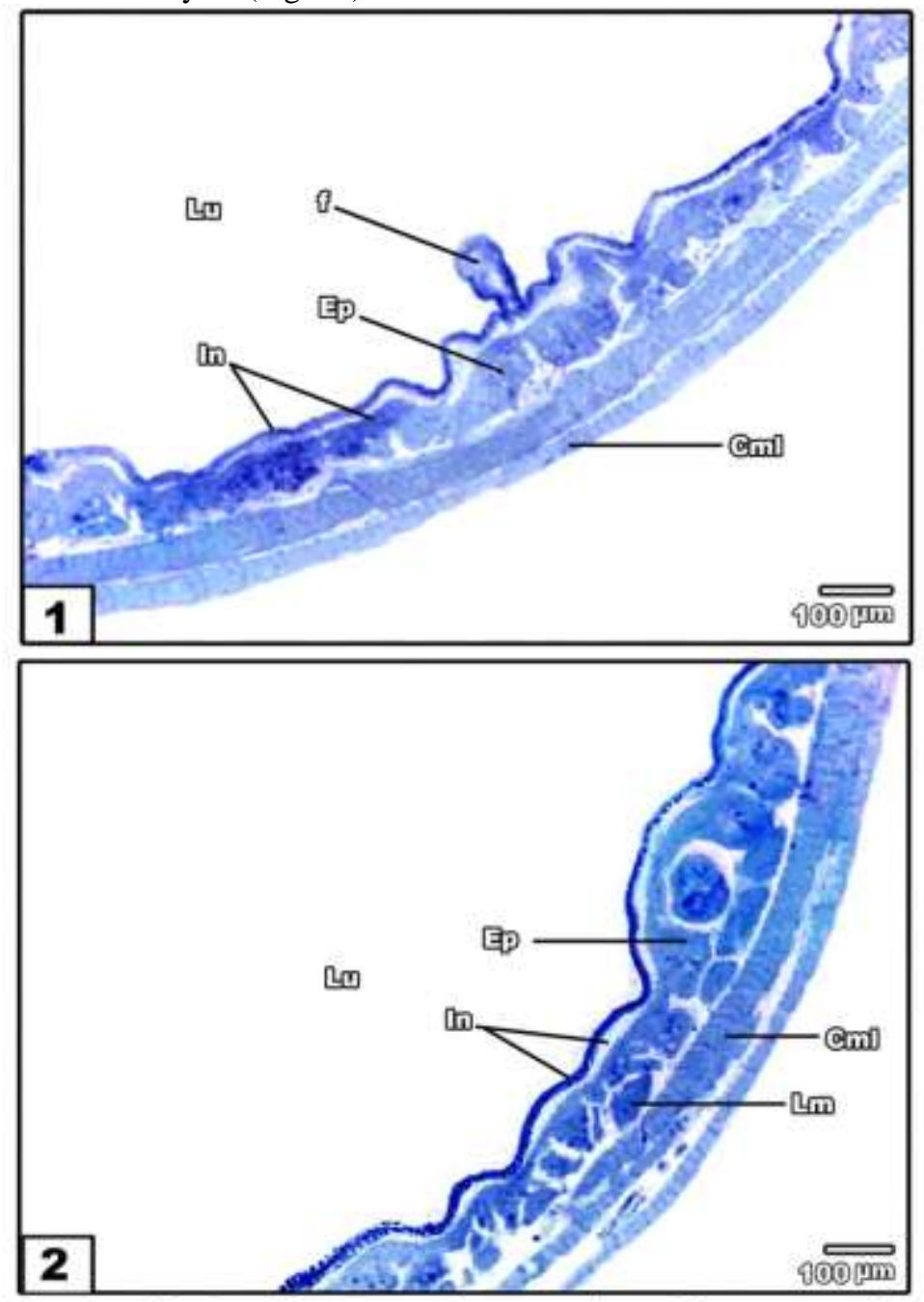

Figs. 1 and 2: Semithin sectors of cross section of the most anterior part of the crop. Circular muscle layer $(\mathrm{Cml})$, longitudinal muscles $(\mathrm{Lm})$, epithelium (Ep), intima (In), lumen (Lu) and fold (f). 

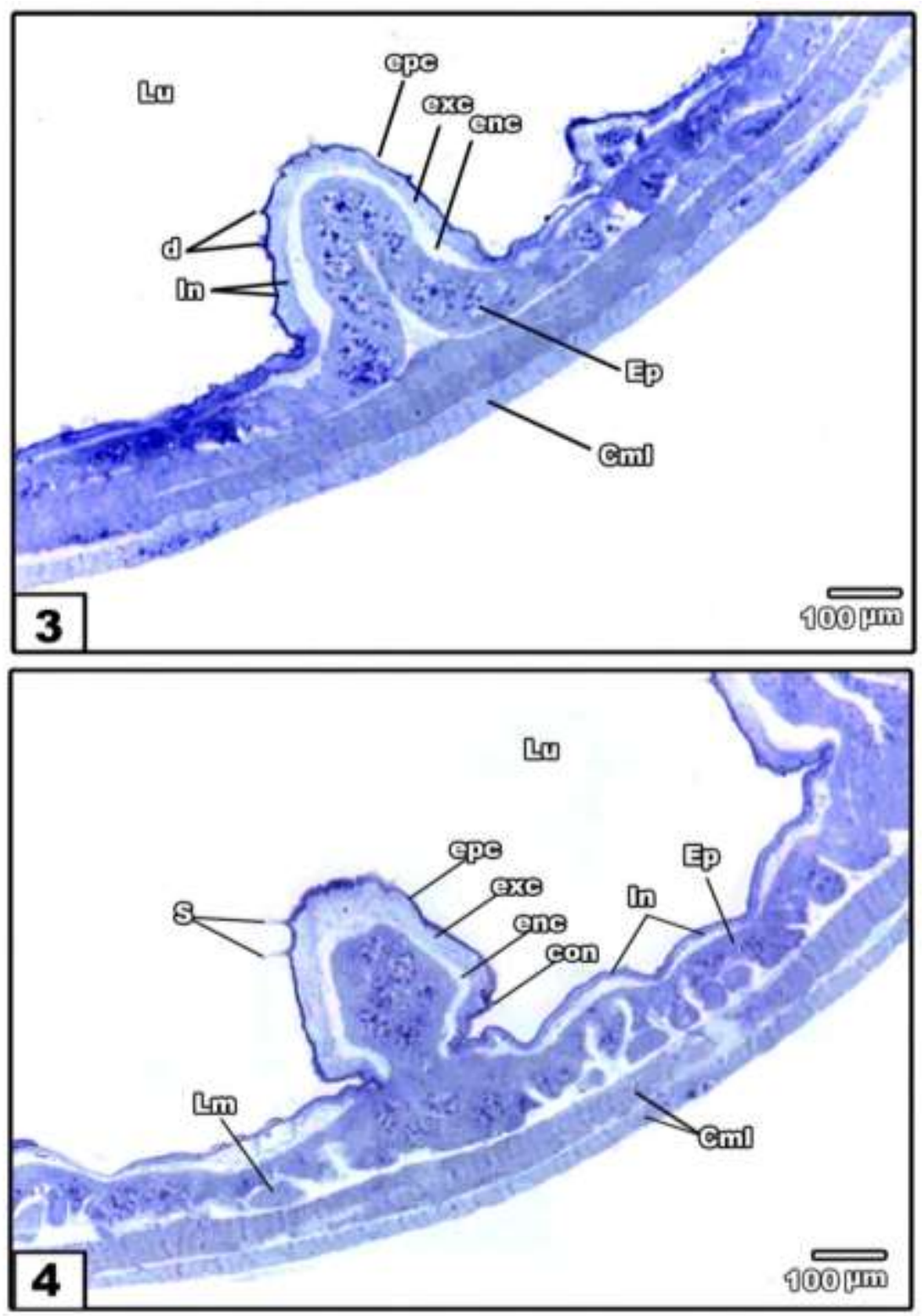

Figs. 3 and 4: Semithin sectors of cross section of the posterior part of the crop. Circular muscle layer $(\mathrm{Cml})$, longitudinal muscles $(\mathrm{Lm})$, epithelium (Ep), intima (In), lumen (Lu), epicuticle (epc), exocuticle (exc), endocuticle (enc), constriction (con), denticles (d) and spinules (s). 


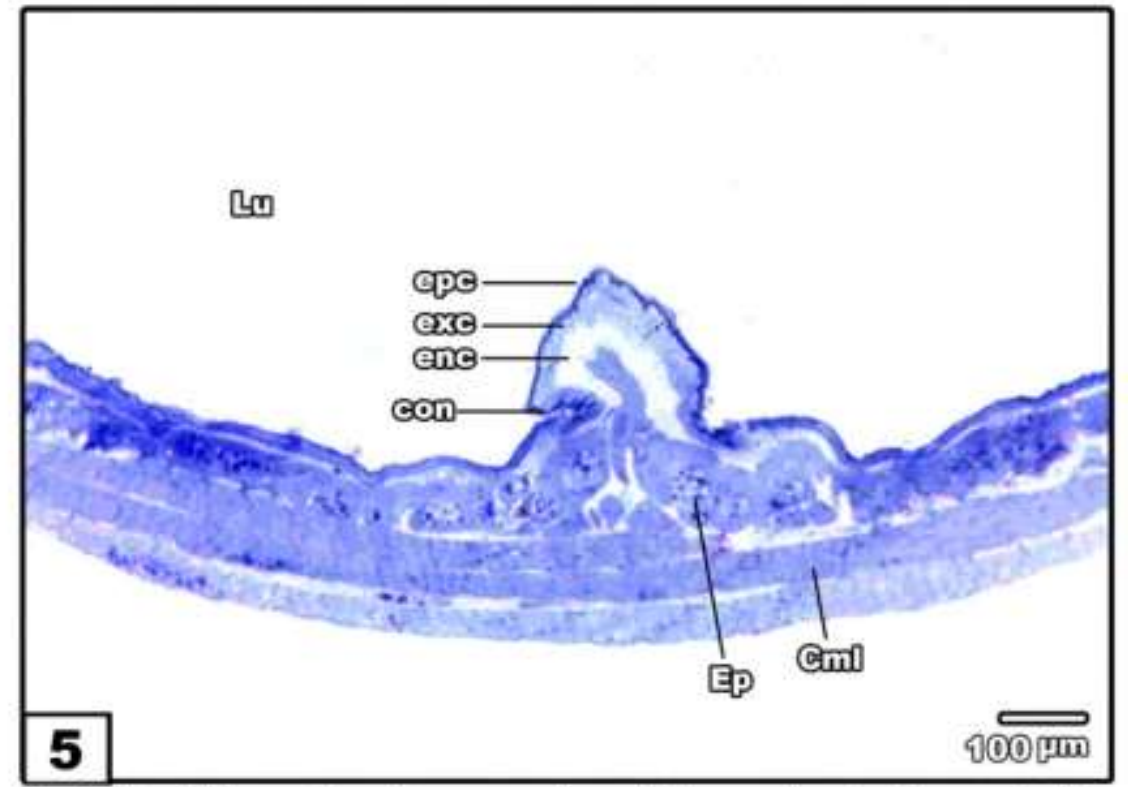

Fig. 5: Semithin sector of eross section of the most posterior part of the crop. Circular muscle layer $(\mathrm{Cml})$, epithelium (Ep), lumen ( $\mathrm{Lu})$, epicuticle (epc), exocuticle (exc), endocuticle (enc), constriction (con).

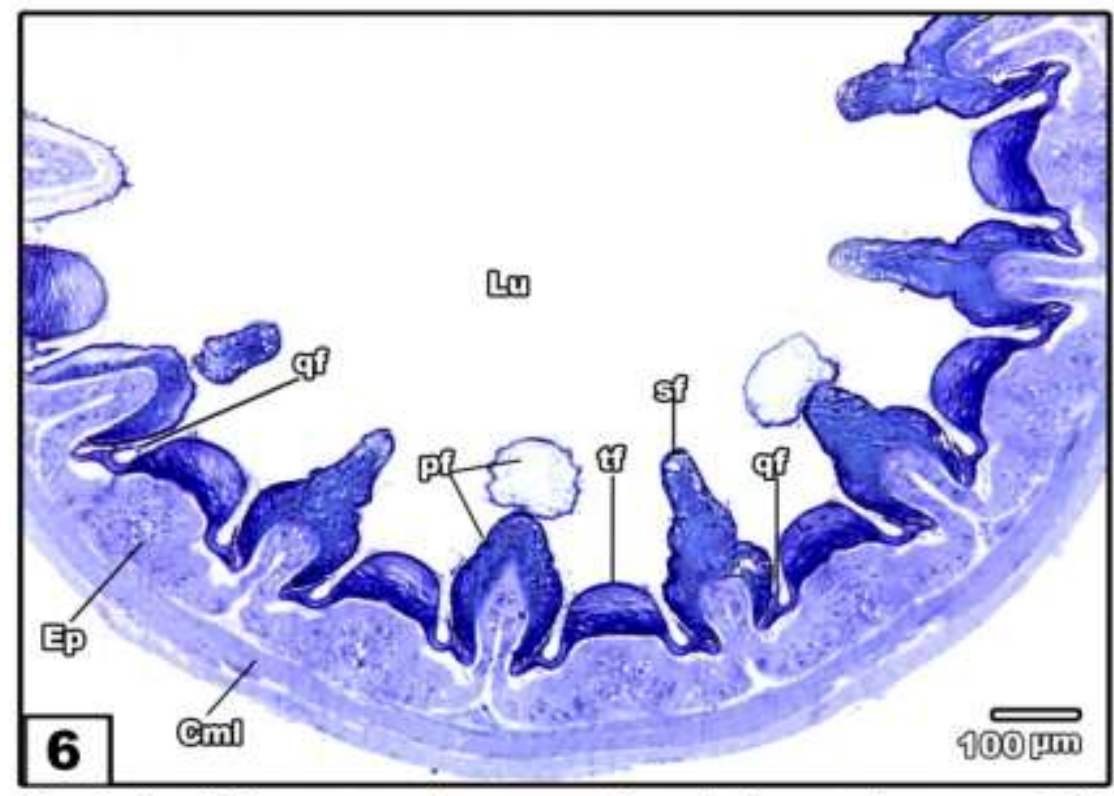

Fig. 6: Semithin sector of cross section of the anterior part of the proventriculus. Circular muscle layer $(\mathrm{Cml})$, epithelium (Ep), lumen $(\mathrm{Lu})$, primary fold (pf), secondary fold (sf), tertiary fold (tf) and quaternary fold (qf). 


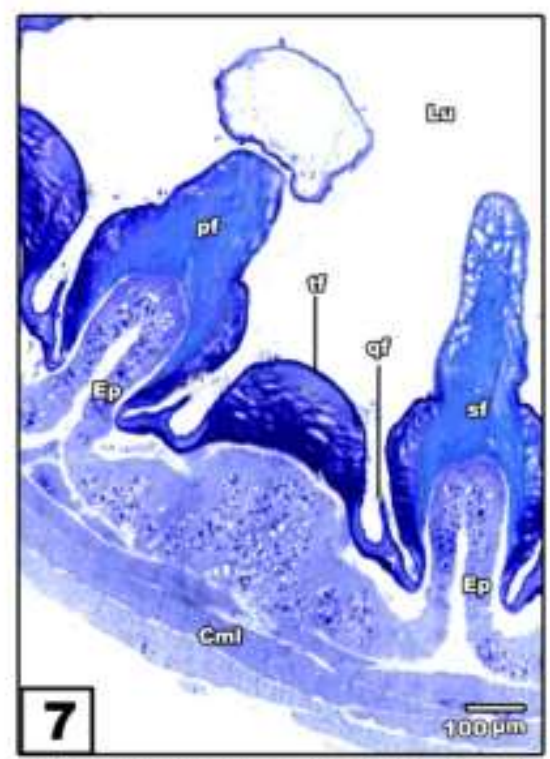

Fig. 7: Semithin sector of cross section of the anterior part of the proventriculus showing the difference between the four types of folds. The circular muscle layer $(\mathrm{Cml})$, epithelium $(\mathrm{Ep})$, lumen $(\mathrm{Lu})$, primary fold (pf), secondary fold (sf), tertiary fold (tf) and quaternary fold (qf).

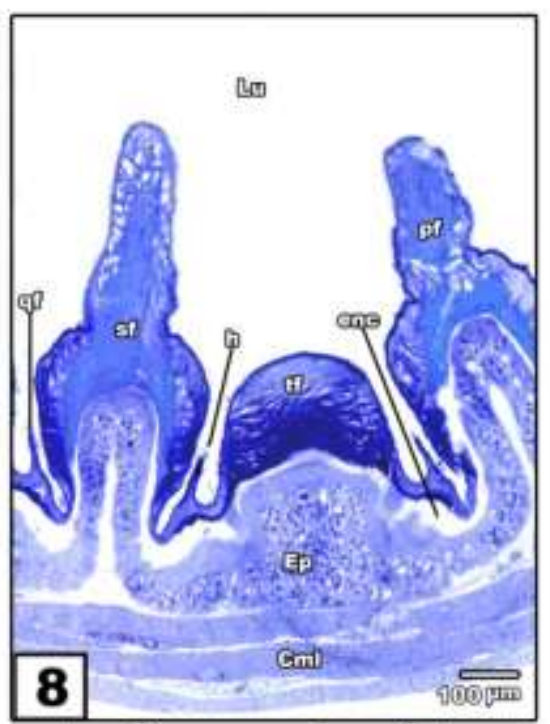

Fig. 8: Semithin sector of cross section of the anterior part of the proventriculus showing the epithelial layer involved in the folds. The circular muscle layer $(\mathrm{Cml})$, epithelium (Ep), lumen $(\mathrm{Lu})$, primary fold (pf), secondary fold ( $(\mathrm{f})$, tertiary fold (tf), quaternary fold ( $\mathrm{qf}$ ), fine hairs (h) and endocuticle (enc). 


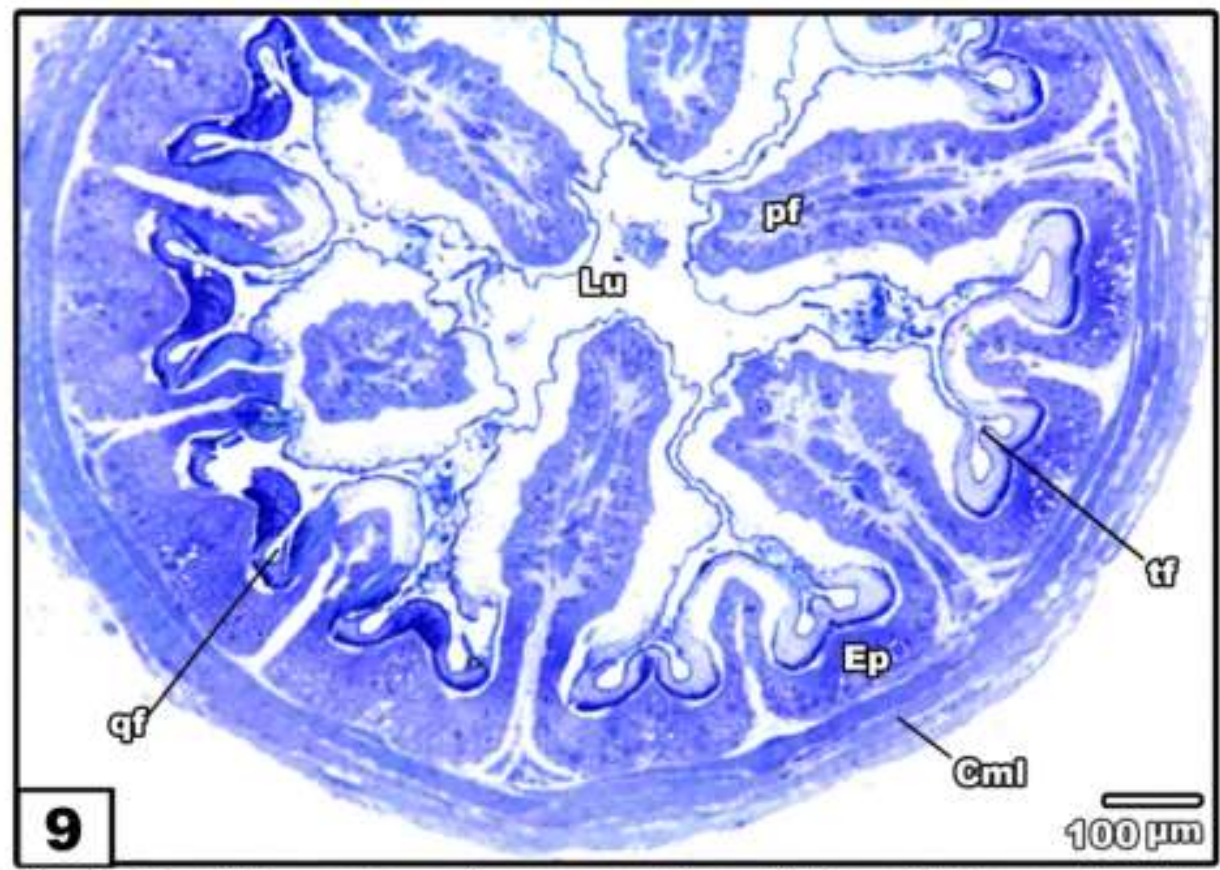

Fig. 9: Semithin sector of cross section of the middle part of the proventriculus showing the great expansion of the primary folds and the reduction in size in the other types of folds. Circular muscle layer $(\mathrm{Cml})$, epithelium (Ep), lumen (Lu), primary fold (pf), secondary fold (sf), tertiary fold (tf) and quaternary fold (qf).

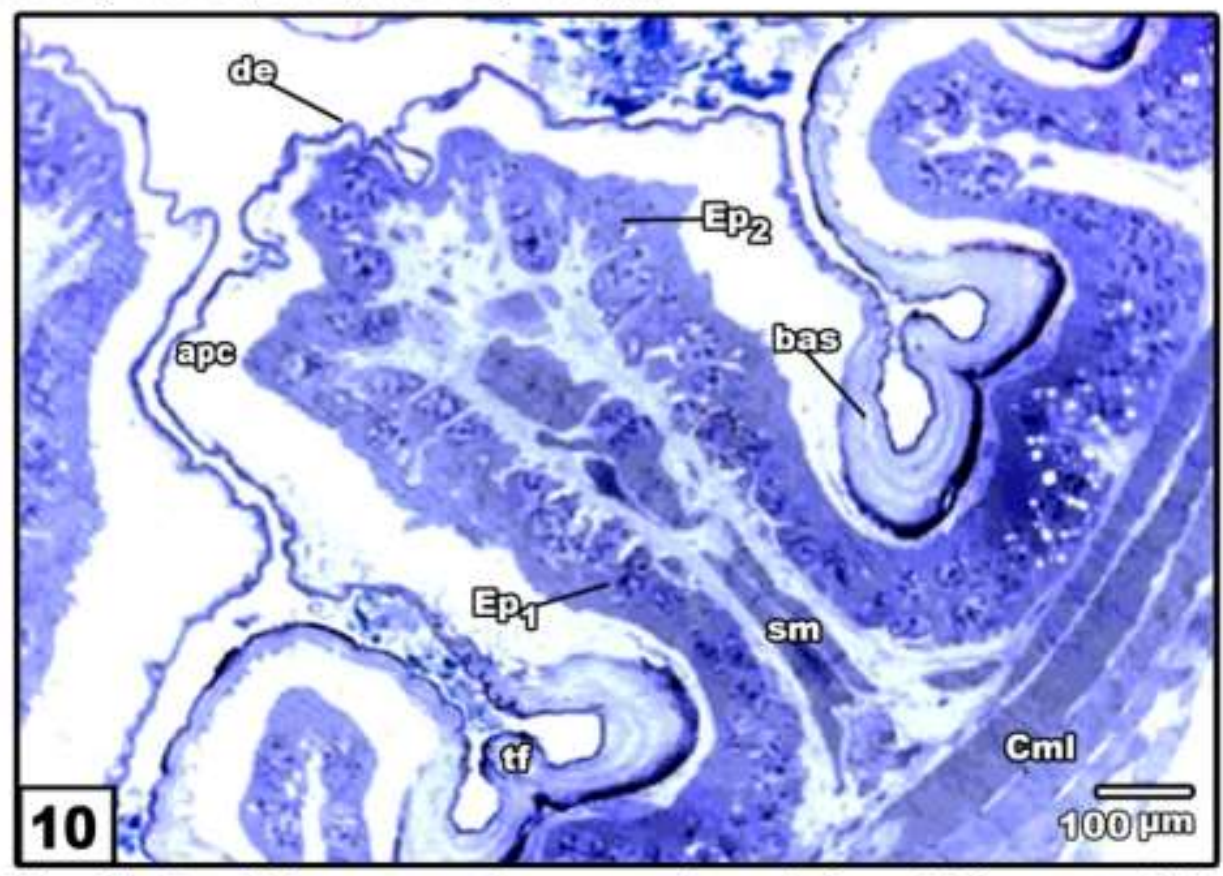

Fig. 10: Semithin sector of cross section of the middle part of the proventriculus showing the primary fold. Denticulated apical part (de), moderately sclerotized basal part (ba), striated muscles (sm), superficial interdigitated epithelium (Ep1), deeply interdigitated epithelium (Ep2) lumen (Lu), primary fold (pf) and tertiary fold (tf). 

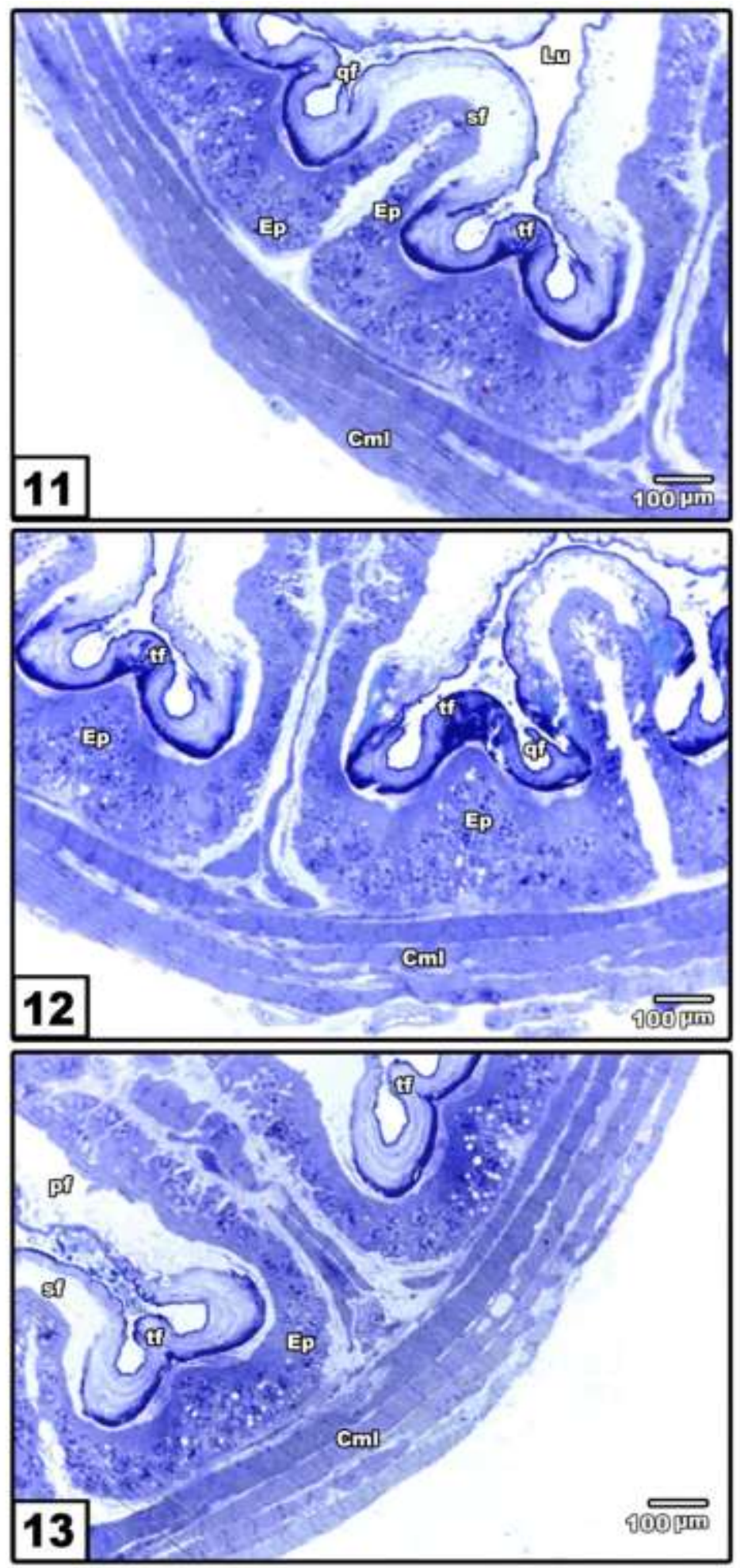

Figs. 11, 12 and 13: Semithin sectors of cross section of the middle part of the proventriculus showing the reduction in size of other types of folds. The circular muscle layer $(\mathrm{Cml})$, epithelium (Ep), lumen ( $\mathrm{Lu})$, secondary fold (sf), tertiary fold (tf) and quaternary fold (qf). 


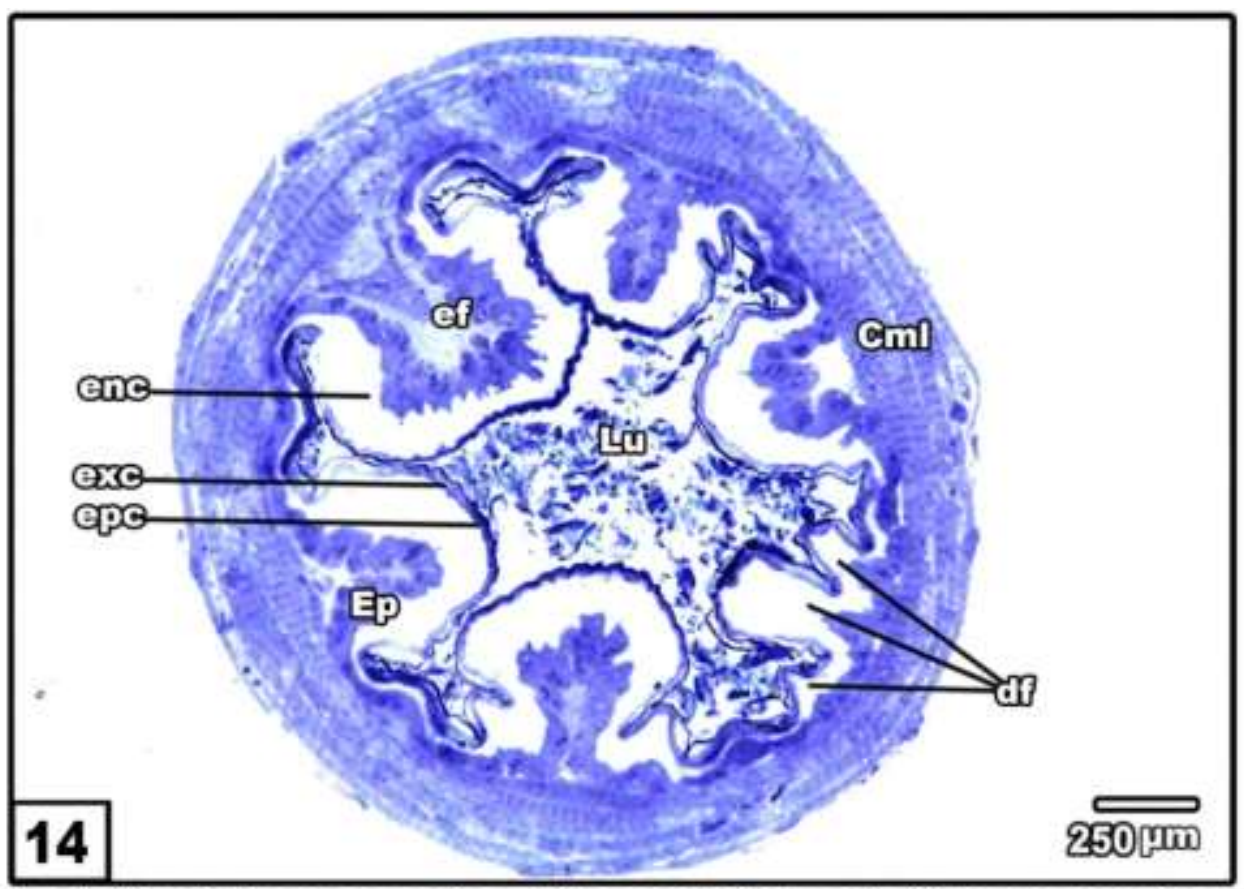

Fig. 14: Semithin cross section of the posterior part of the proventriculus showing the reduction in size and number of folds. Epithelium (Ep), lumen ( $\mathrm{Lu}$ ), extended folds (ef), diminished folds (df), epicuticle (epc), exocuticle (exc), endocuticle (enc) and circular muscle layer $(\mathrm{Cml})$.

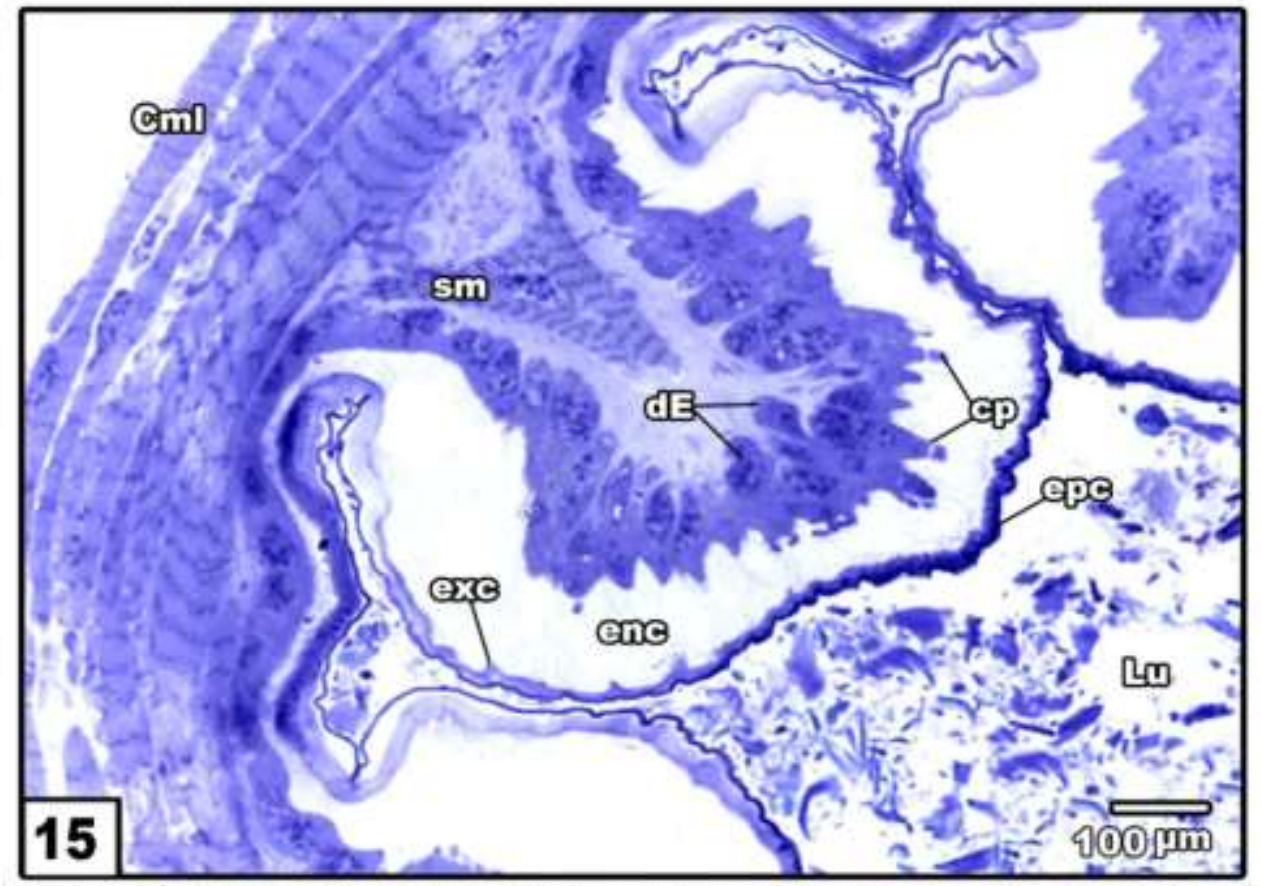

Fig.15. Semithin sector of cross section of the posterior part of the proventriculus showing the largest one of the expanded folds. The circular muscle layer $(\mathrm{Cml})$, digitated epithelium (dE), cytoplasmic processes (cp), epicuticle (epc), exocuticle (exc), endocuticle (enc), striated muscle (sm) and lumen (Lu). 

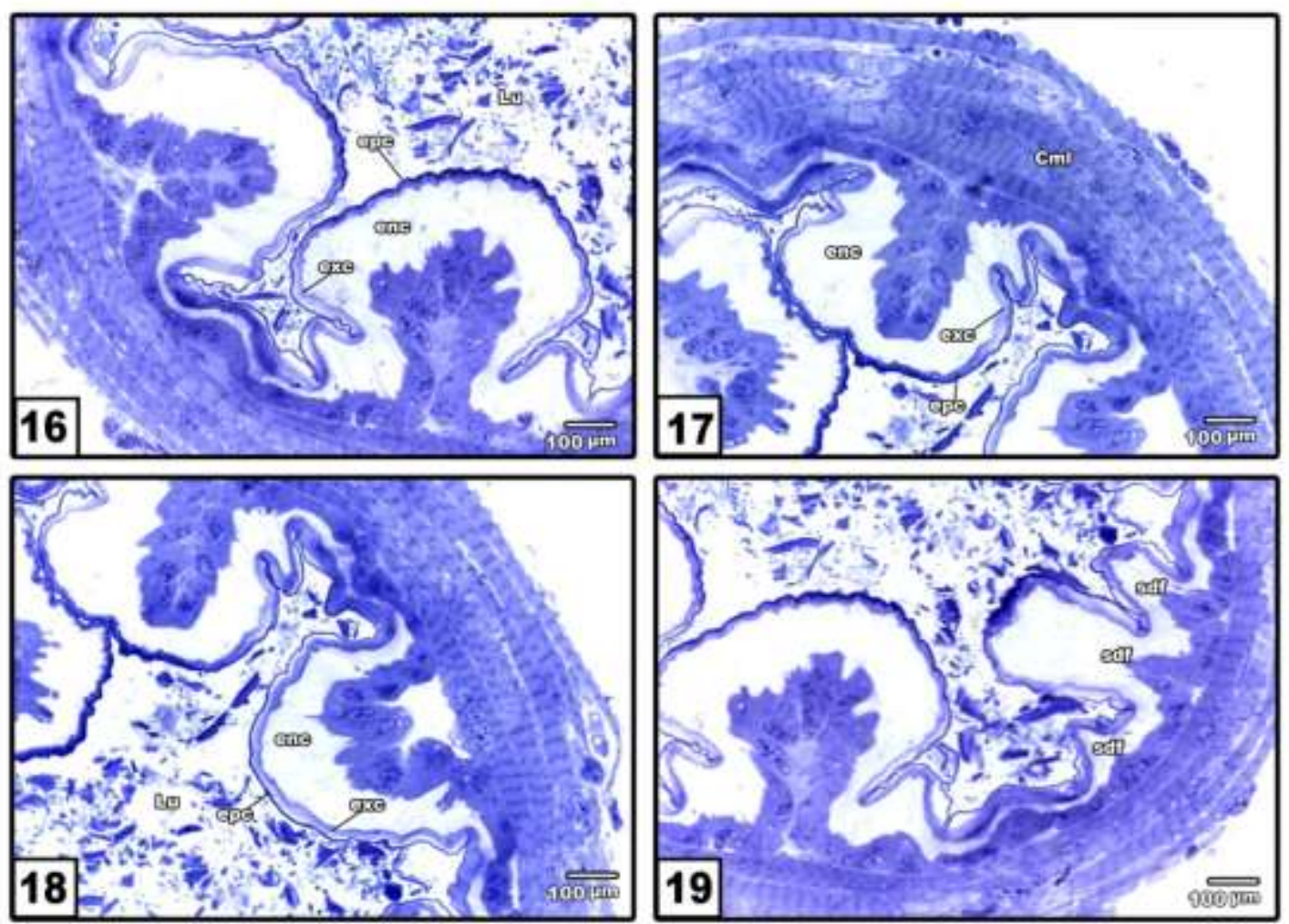

Figs. 16, 17, 18 and 19. Semithin sectors of cross section of the posterior part of the proventriculus showing the successive reduction of the folds and the digitation of the epithelium. Epithelium (Ep), lumen ( $\mathrm{Lu}$ ), epicuticle (epc), exocuticle (exc), endocuticle (enc), successive diminished folds (sdf), and circular muscle layer $(\mathrm{Cml})$. 


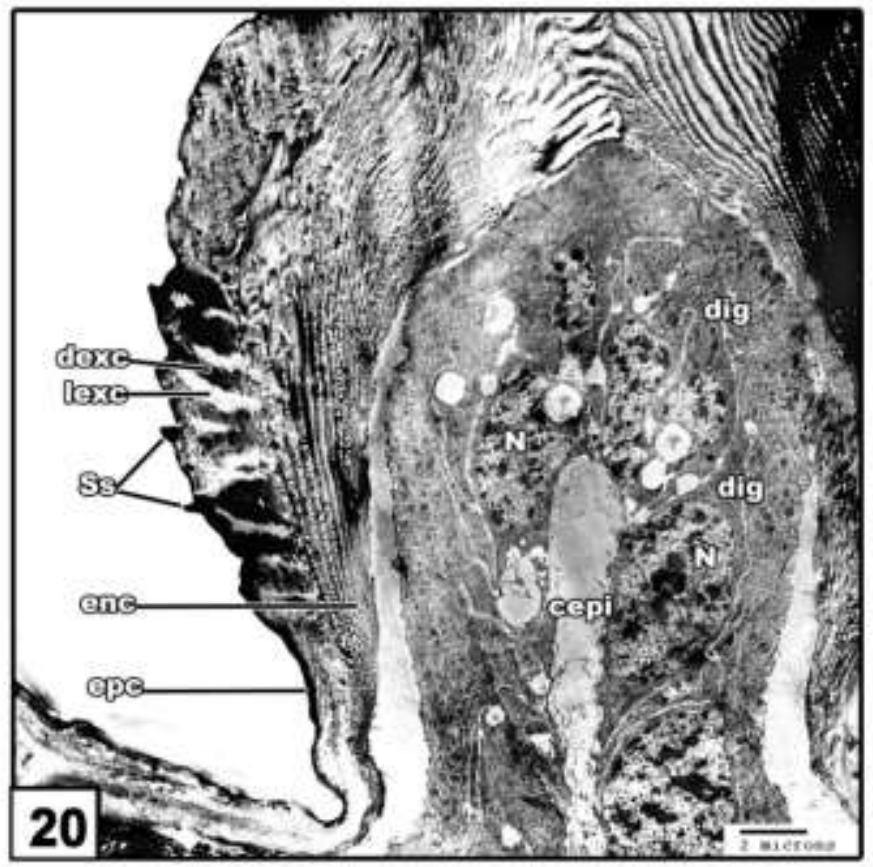

Fig. 20: Ultrathin section of one of the secondary folds. Epicuticle (epc), electron lucent exocuticle layer (lexc), electron dense exocuticle layer (dexc), endocuticle (enc), sharp spines (ss), cavity of epithelial fold (cepi). Nucleus (N) and digitating part (dig).

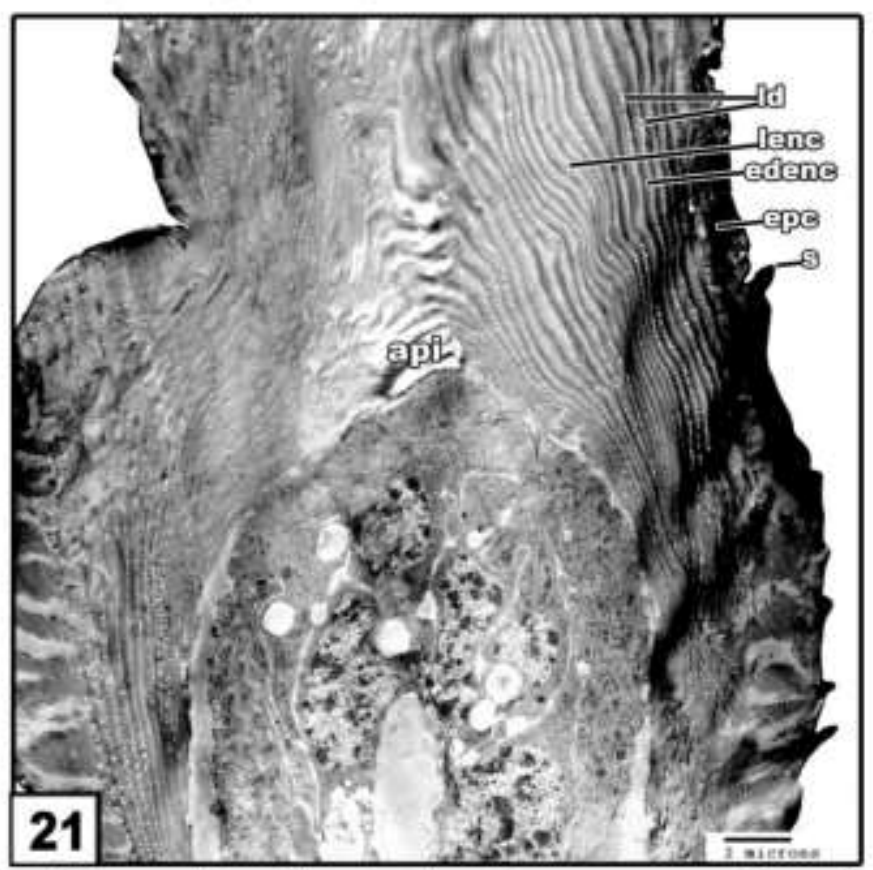

Fig. 21: Ultrathin section illustrating the crown region of one of the secondary folds. Epicuticle (epc), apical part of intima covering the apex of the fold of the secondary type (api), spines (s), electron dense endocuticle layer (edenc), electron lucent endocuticle layer (lenc) and electron lucent dots (ld). 


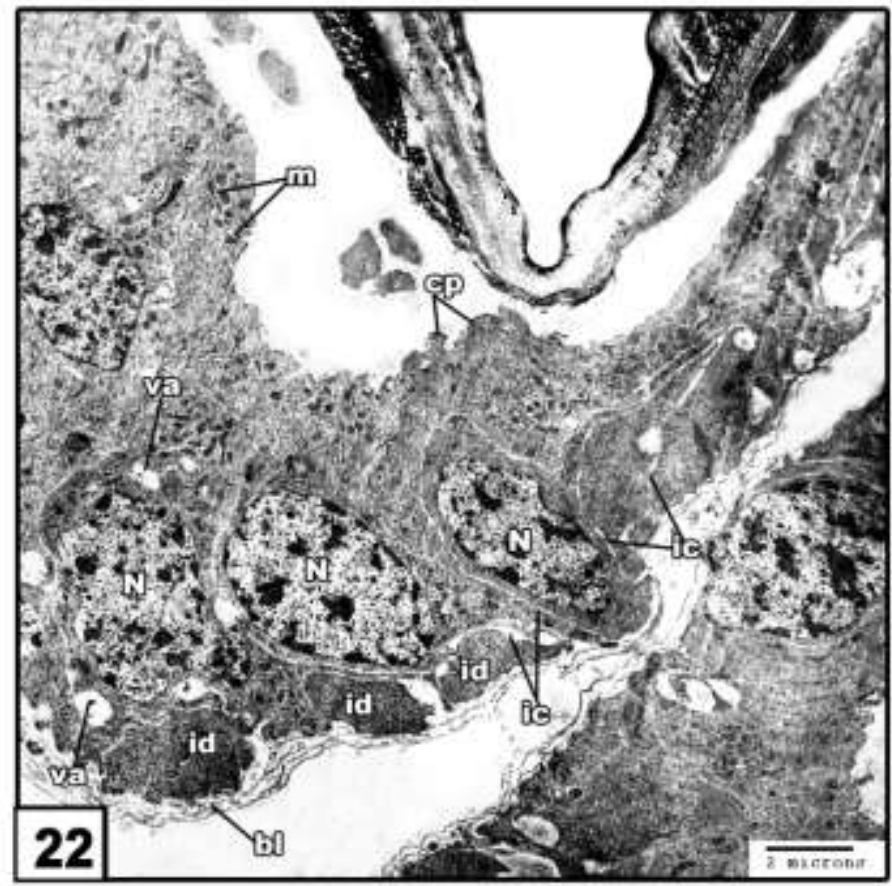

Fig. 22: Ultrathin section of number of epithelial cells of one of the secondary folds. Basal lamina (bl), cytoplasmic processes (cp), intercellular space (ic), interdigitated process (id), mitochondria $(\mathrm{m})$, nucleus $(\mathrm{N})$ and vacuole (va). Scale bar, 2 microns.

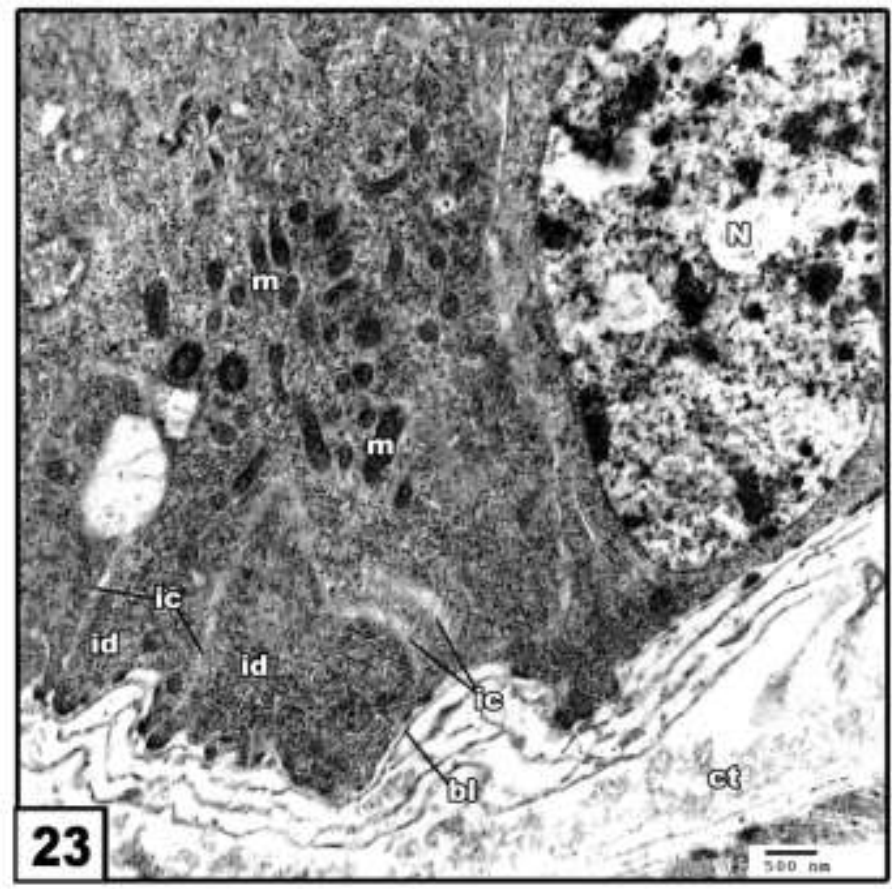

Fig. 23: Ultrathin section of the basal part of epithelial cells of one of the secondary folds. Basal lamina (bl), intercellular space (ic), interdigitated process (id), mitochondria ( $\mathrm{m}$ ), nucleus $(\mathrm{N})$ and connective tissue (ct). Scale bar, $500 \mathrm{~nm}$. 


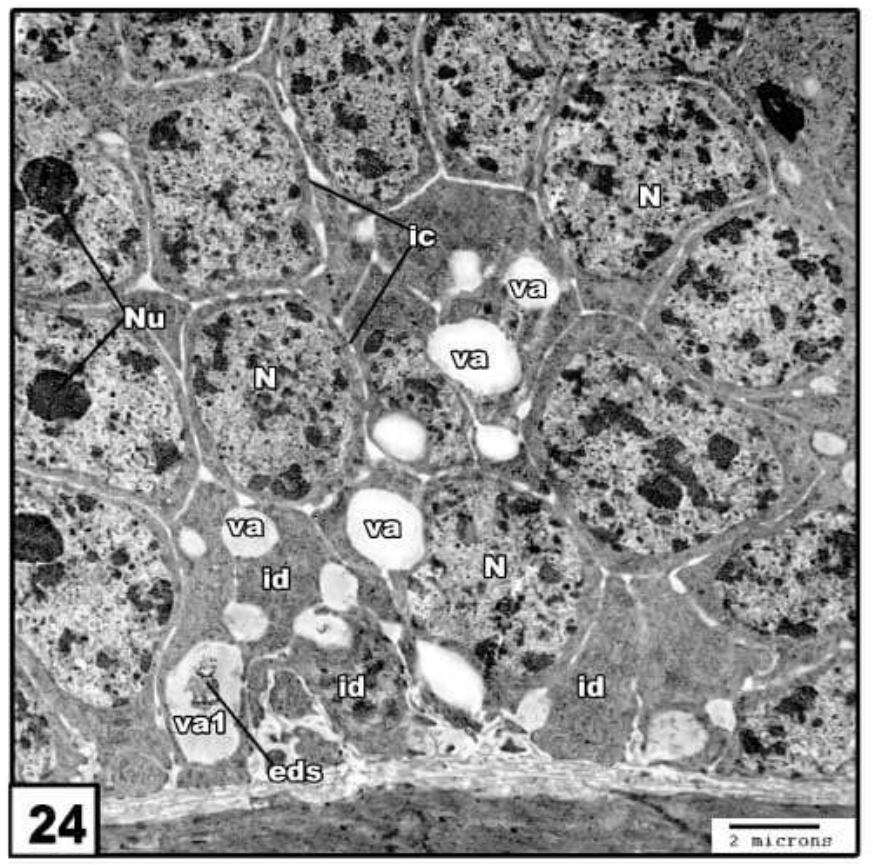

Fig. 24: Ultrathin section of number of epithelial cells of one of the tertiary folds. Intercellular space (ic), interdigitated process (id), nucleus $(\mathrm{N})$, nucleolus (n), vacuole (va), vacuole containing electron dense substance (va1) and electron dense substance (eds). Scale bar, 2 microns.

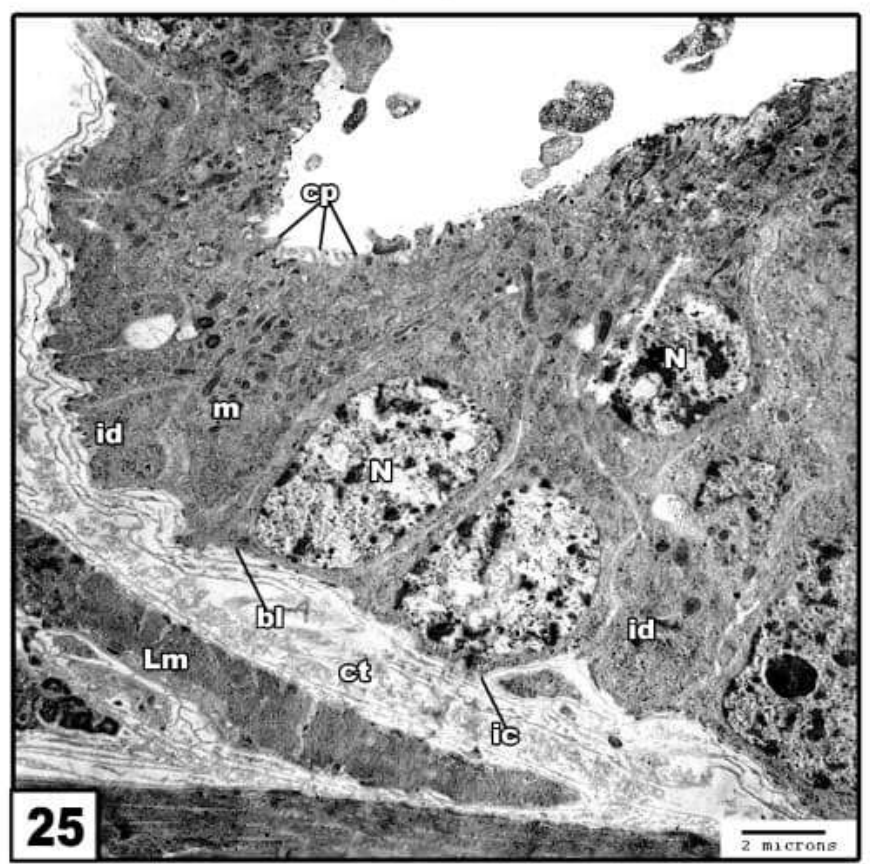

Fig. 25: Ultrathin section of number of epithelial cells in between folds. Basal lamina (bl), cytoplasmic processes of the apical part of the epithelial cells (cp), intercellular space connected with the underlying connective tissue and muscles (ic), interdigitated process (id), mitochondria (m), nucleus (N), connective tissue (ct) and longitudinal muscles (Lm). Scale bar, 2 microns. 


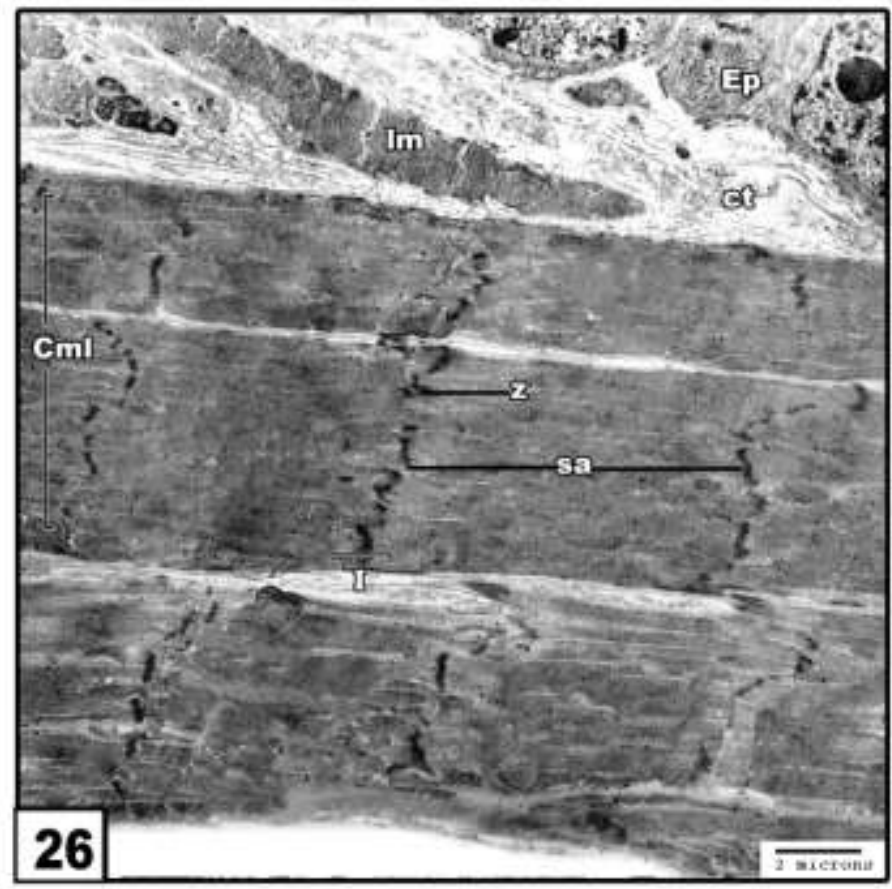

Fig. 26: Ultrathin section of the proventriculus illustrating the muscle layers. Epithelial cells (ep), connective tissue (ct), longitudinal muscles ( $\mathrm{lm}$ ) circular muscles $(\mathrm{cml}), \mathrm{I}$ band $(\mathrm{I}), \mathrm{Z}$ line $(\mathrm{Z})$ and sarcomere (sa).

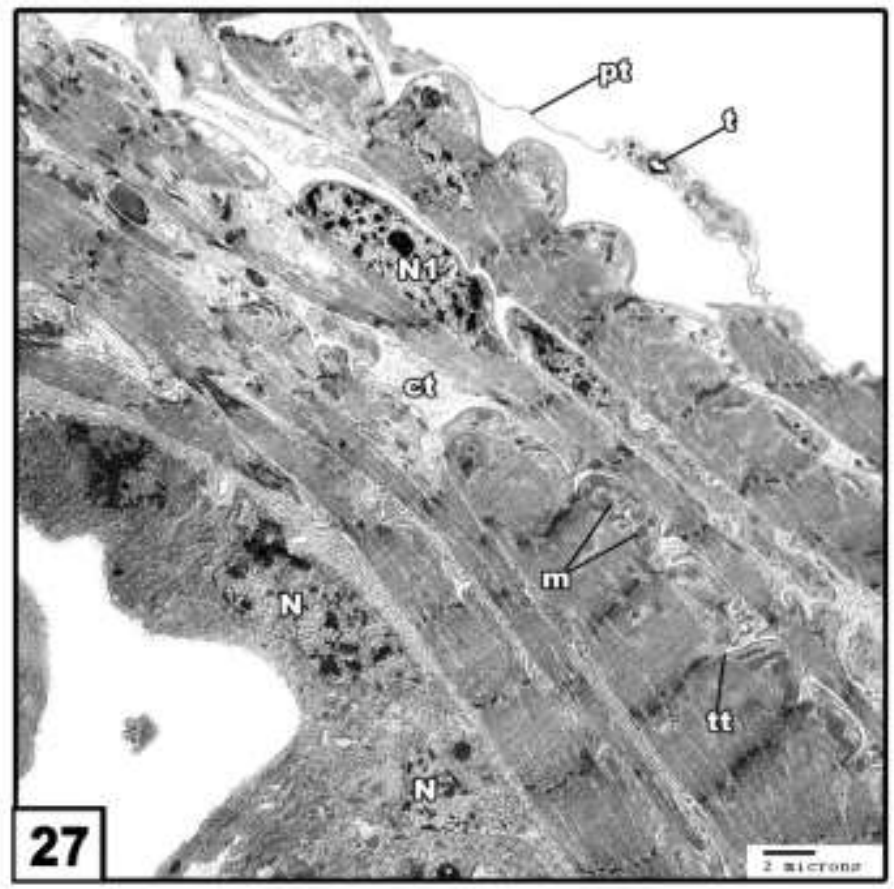

Fig. 27: Ultrathin section of the proventriculus illustrating the circular muscle layers. Peritoneum $(\mathrm{Pt})$, tracheole $(\mathrm{t})$, connective tissue $(\mathrm{ct})$, nucleus of the epithelial cell $(\mathrm{N})$, nucleus of muscle cell (N1), mitochondria (M) and T-tubule ( $\mathrm{tt})$. 


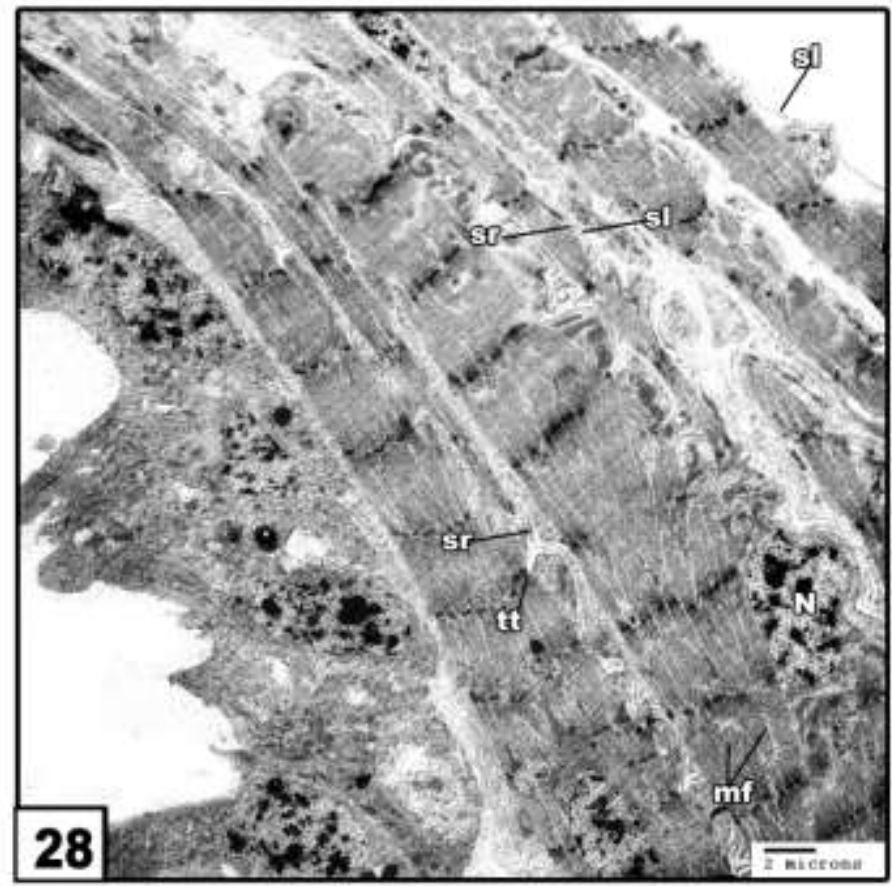

Fig. 28: Ultrathin section of the proventriculus illustrating the circular muscle layers. Sarcoplasmic reticulum (sr), sarcolemma (sl), nucleus (N), T-tubule (tt) and myofibril $(\mathrm{mf})$.

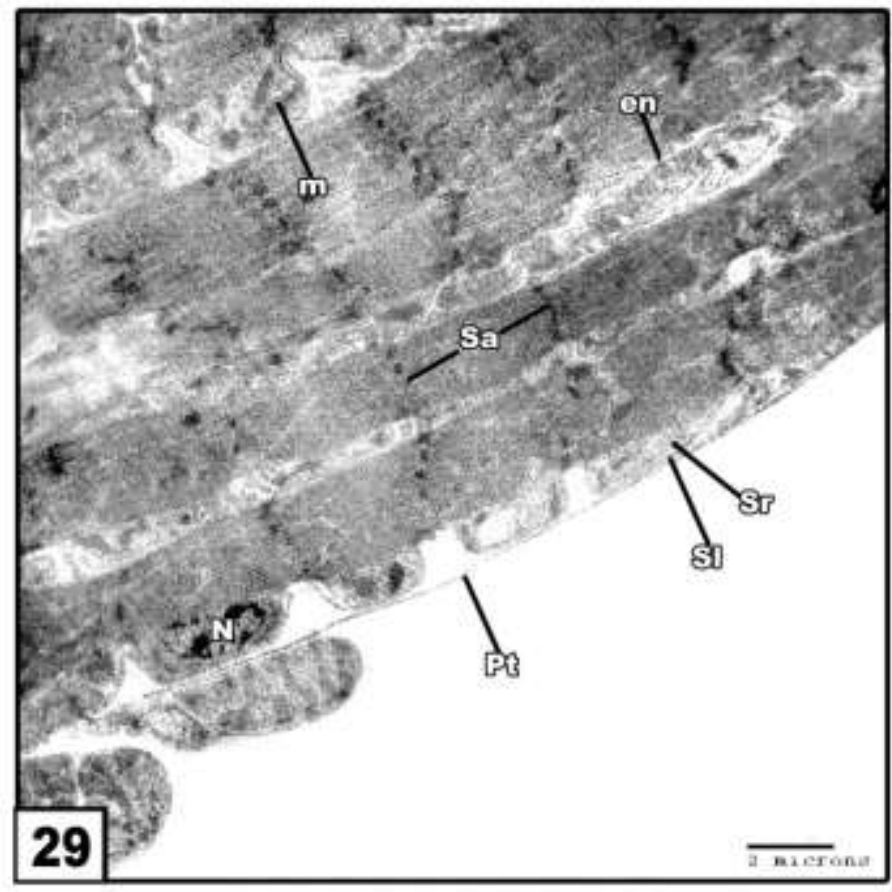

Fig. 29: Ultrathin section of the proventriculus illustrating the circular muscle layers. Peritoneum (Pt), Sarcoplasmic reticulum (sr), sarcolemma (sl), nucleus (N), mitochondria (M), sarcomere (sa), and endomysium (en). 


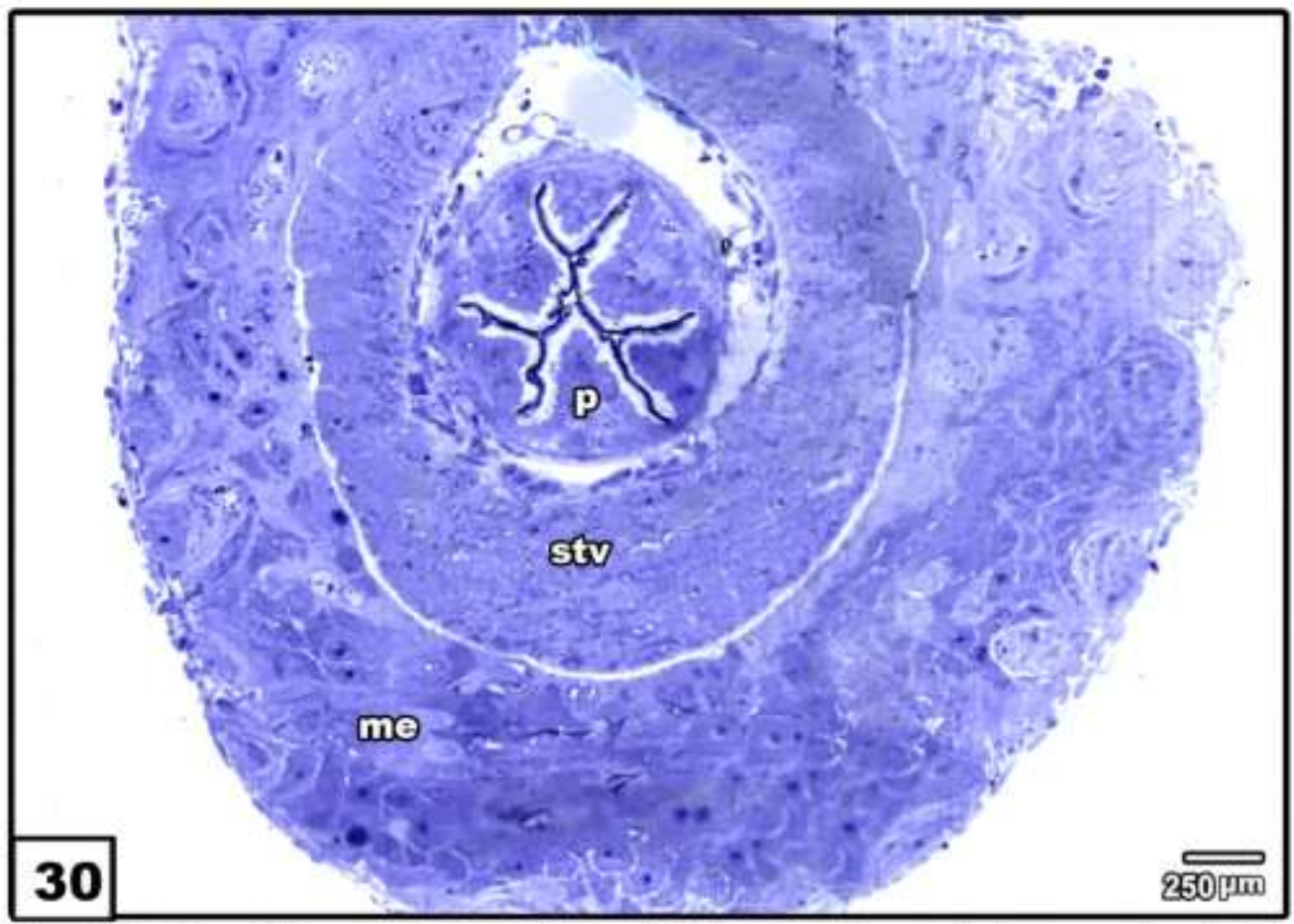

Fig. 30: Semithin cross section of the most posterior part of the proventriculus. Proventriculus (p), stomodeal valve (stv) and mesentron (me).

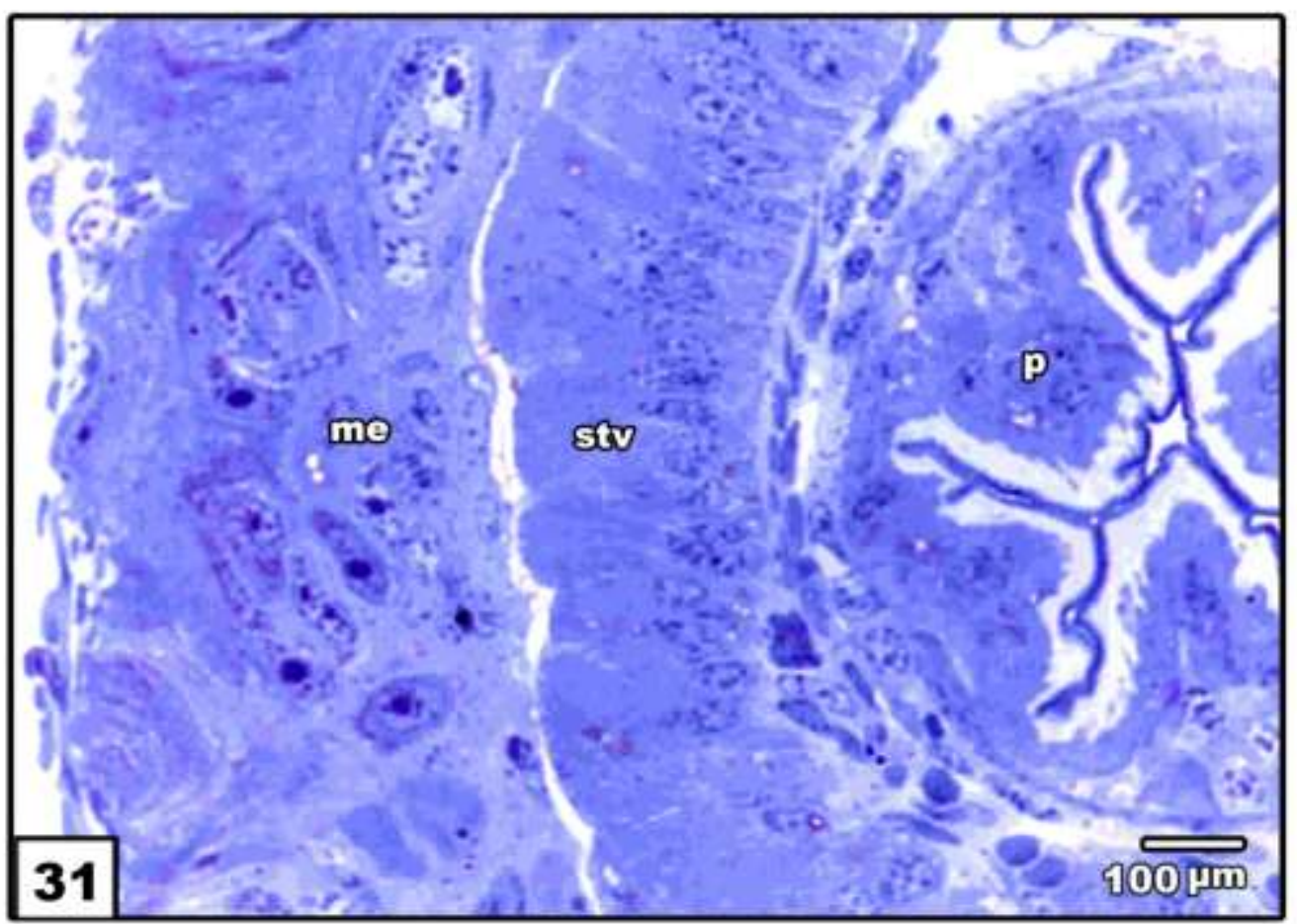

Fig. 31: Semithin sector illustrating the proventriculus surrounded by the stomodeal valve and the most anterior part of the mesentron. Proventriculus (p), stomodeal valve (stv) and mesentron (me). 


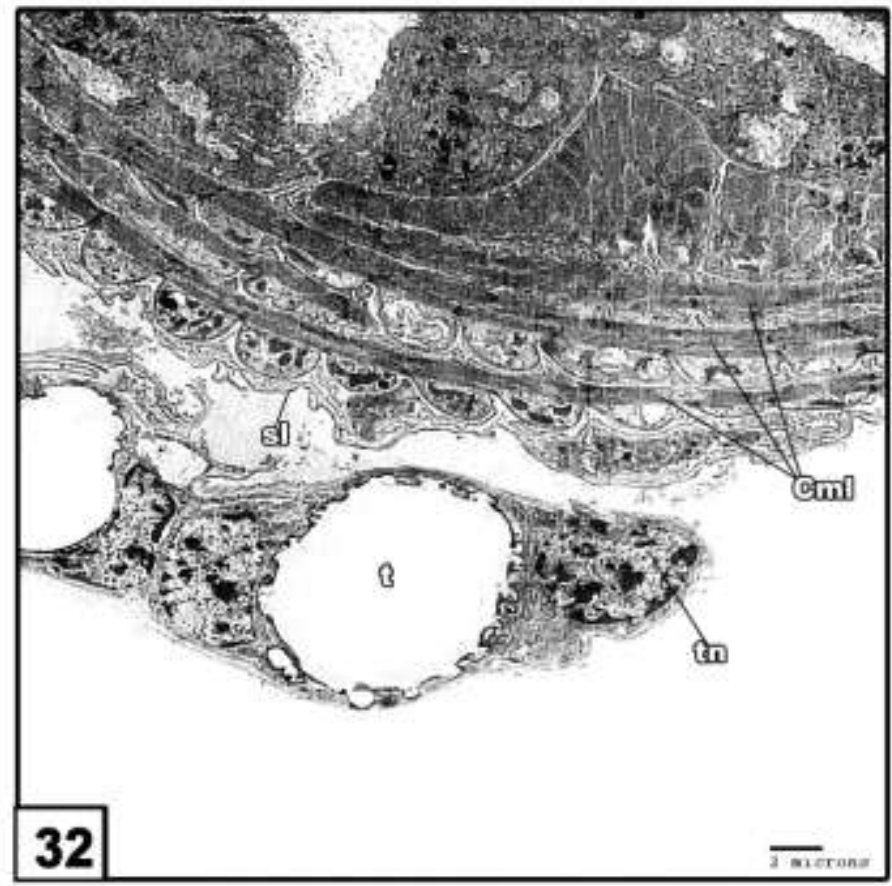

Fig. 32: Ultrathin section showing the continuous circular muscle layer enclosing the most posterior part of the proventriculus. Circular muscles $(\mathrm{cml})$, sarcolemma $(\mathrm{sl})$, tracheoles $(\mathrm{t})$ and tracheoles cell nucleus $(\mathrm{tn})$.

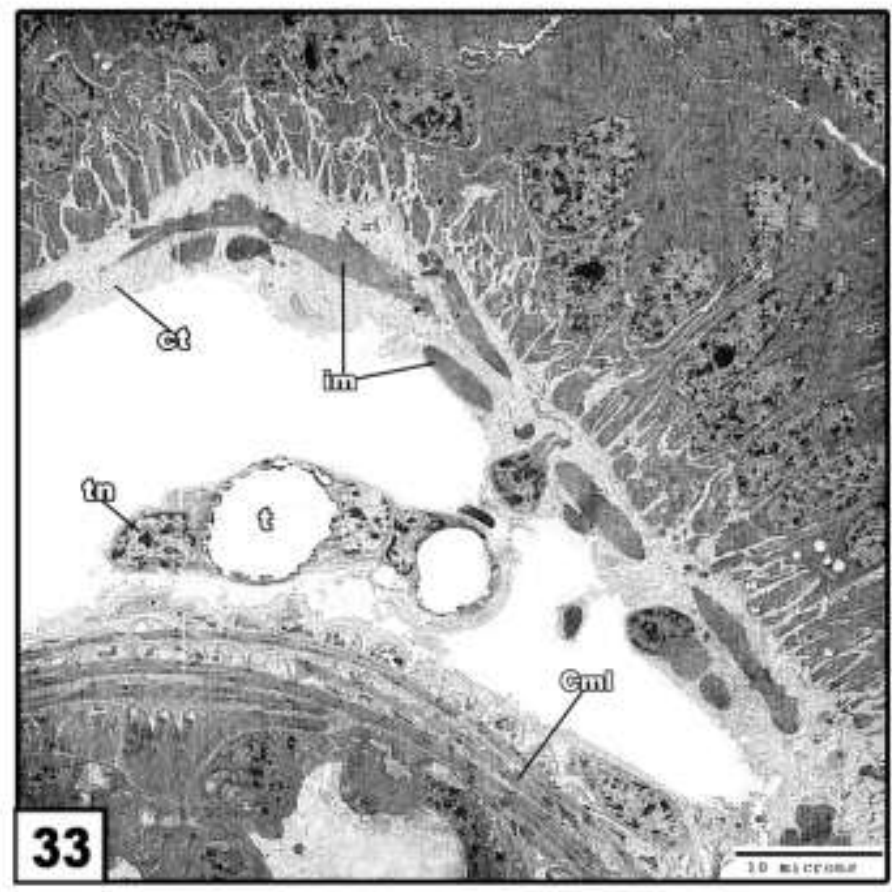

Fig. 33: Ultrathin section showing the muscles of the proventriculus and stomodeal valve facing each other. Continuous circular muscles of the proventriculus $(\mathrm{cml})$, interrupted circular muscle layer of the valve (im), connective tissue (ct), tracheoles (t) and tracheoles cell nucleus (tn). 

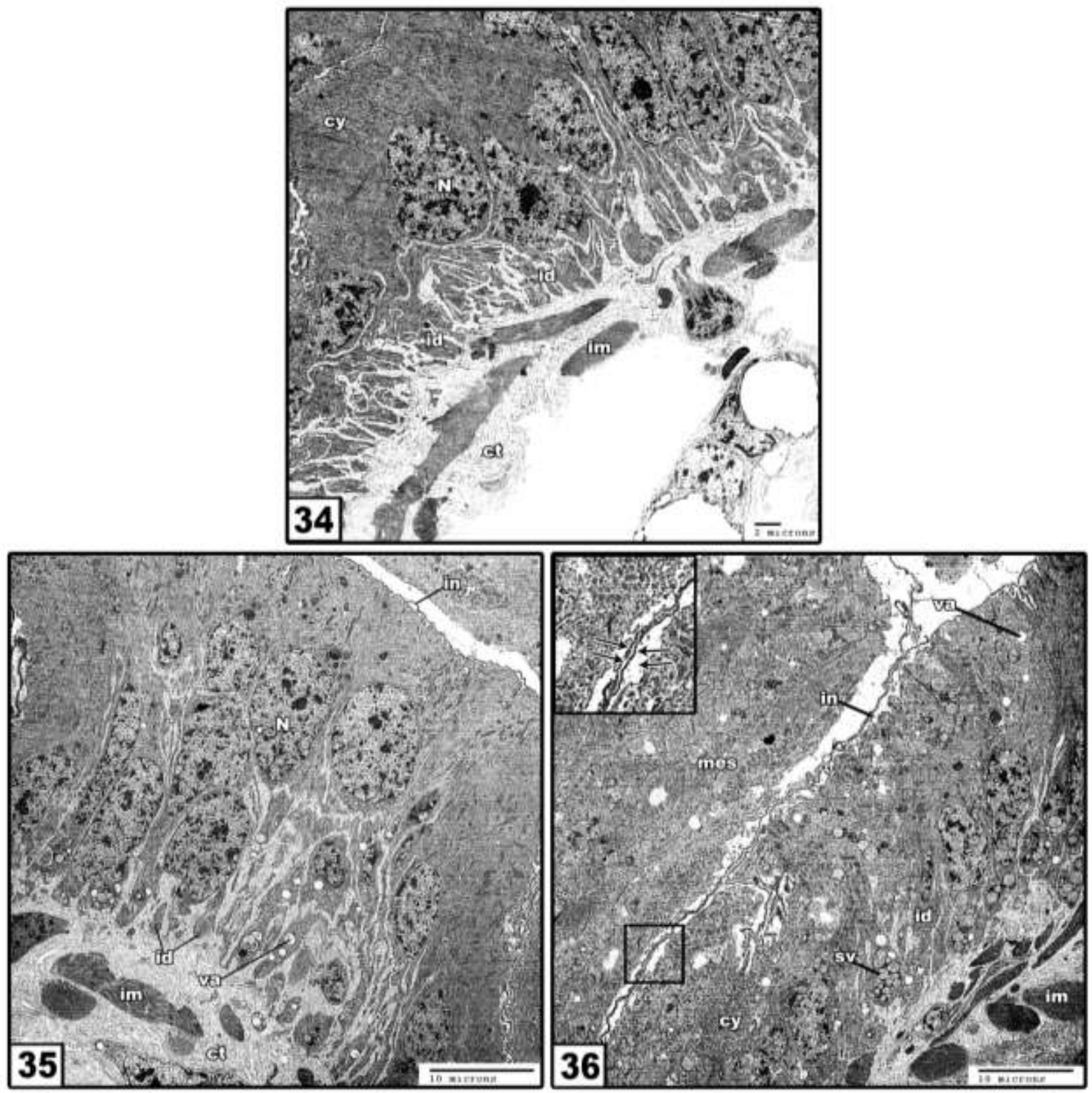

Figs. 34, 35 and 36: Ultrathin sections of stomodeal valve. Interrupted circular muscle layer of the valve (im), connective tissue (ct), cytoplasm (cy), nucleus (N) interdigitations (id), intima (in), mesentron (mes), secretory vacuole (sva) and vacuole (va). Note: fig. 36 inset illustrat four layers indecated by arrows: 2 electron dens linear layers inclosing one electron leusent narrow layer and an electron leucent layer facing the epithelial cells. 


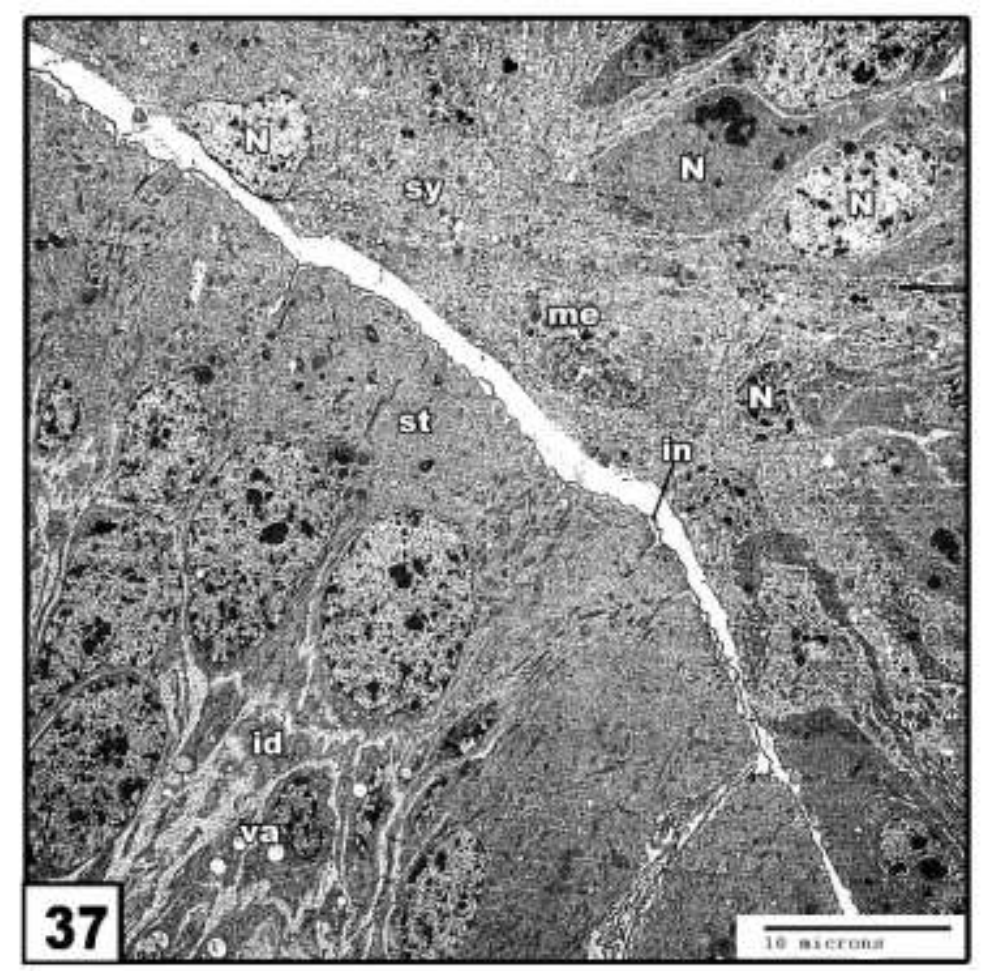

Fig. 37: Ultrathin section showing the most anterior part of the mesentron surrounding the stomodeal valve. Stomodeal valve (stv) mesentron (me), syncytium (sy), nucleus (N), intima (In), interdigitations (id) and vacuoles (va).

\section{Discussion:-}

The folds of the crop of the studied species of termite are shallow and varied in shape and number all over the crop wall. The chitinized layer is thin without any speculations on its luminal surface. While in termite Nasutitermes takasagoensis (Tokuda et al; 2001) there are compact grinding dental plates. The posterior part of the crop of periplaneta americana has thick chitinization that formed dagger like spines ( Krishnan, 1986). The chitinization in $P$. australasiae has a triangular shape with blunt ends (Krishnan, 1986). The intima form scattered spines in the case of Sitophilus granarius crop (Baker et al; 1984).

The proventriculus of periplaneta Americana formed of anterior (dental belt) and posterior (pulvillar belt) regions. The dental belt has four different types of folds. It has six long strong primary dentacles. The space between each two successive primary dentacles contains toothed secondary dentacles, thick chitinized hairy interdentry fold and a thick hairy intercalary fold ( Krishnan, 1986). The pulvillar belt has anterior and posterior cushions. The anterior cushions characterized by small blunt triangular spines and set below the primary dentacles. The posterior cushions set between the secondary dentacles. It has densely packed hairs forming meshwork ( Krishnan, 1986). The upper surface of the proventriculus of turtle ant, Zacrypttocerus rohweri, looks like the cap of typical mushroom. Its wall is heavily chitinized and covered by clusters of heavily branched spines that lined the channels which radiated from the center of the upper surface (Roche and Wheeler, 1997). Morphological structure of the proventriculus of Corbiculate apinae (Hymenoptera, Apidae), solitary bees, and tribe Augochlorini was clarified bySerrão, 2001; Serrão, 2005 and Serrão, 2007. The structures have the same basic pattern of the proventriculus of bees as it is a bulb shape located inside the crop and its wall formed of four thick folds each consists of an apical hairy movable part and a chitinized basal plate. The wall of the proventriculus of Gryllus pennsylvanicus formed of six dental folds separated from each other by chitinous partitions. Each dental fold consisted of seven teeth, arranged as following: long median tooth has one tooth on each side, two teeth behind it and a brush like process next to the partition on each side, (DuPorte, 1918). The proventriculus of Mastotermes darwininsis was studied by scanning electron microscopy (Czolij et al., 1984). Its wall has forty eight folds of similar and different sized structure. The number of similar folds varies greatly. They are as following: six of large dental plates, six of second order folds, twelve of 
third order folds and twenty four of fourth order folds. The armature of the proventriculus of Gryllus assimilis was revealed by scanning studies (Fontanetti and Zefa, 2000). It is formed of six rows of sclerotized appendices; each row has twelve sclerotized appendices. Each sclerotized appendix contains one median tooth and two lateral teeth. The median tooth ended with seven dentacles, the same lateral teeth each has seven dentacles. The sculpture of the proventriculus of Mellanogryllus desertus formed of six sclerotized appendices- each constituted of one middle tooth and two lateral teeth, six sclerotized partitions, and 12 sclerotized lobes ( Cakici and Ergen, 2012). Kalotermes flavicollis has a muscular proventriculus (Noirot and Noirot-Timothée, 1969). Its armature formed of 4 different types of folds with total number of 48. This number includes 6 folds of first order, 6 folds of second order, 12 folds of third order and 24 folds of fourth order. The differences between the first and second order is in the thickening and chitinization of intima. Third order folds are less protruding and alternate with the first and second order. The fourth order represented by thin long sclerotized folds.

From the previous interpretations, it is obvious that the folds of the proventriculus vary in size and number among different insects. The number of the folds in Periplaneta americana is twenty four, in Gryllus pennsylvanicus is forty eight, in Mellanogryllus desertus is thirty six. In two species of termites Mastotermes darwininsis and Kalotermes flavicollis, the proventriculus has forty eight folds.

The termite species of the present article has forty eight folds. The folds have the same sculpture and arrangement as in Kalotermes flavicollis. The forty eight folds are present in the widest part of the proventriculus. The size of the folds is diminished and their number is reduced as the proventriculus extends backward. The backward extension is encircled by a fold of the foregut wall forming the stomodeal valve which invaginated within the anterior part of the mesentron. There is a progressive reduction in the size and number of the folds within the mesenteric valve. The main function of the valve is to regulate the passage of the foregut contents into the mesentron (Tokuda et al., 2001).

The apical surface of the epithelial layer of the proventriculus of carpenter bee, Xylocopa virginica and termite species Macrotermes darwininsis, has numerous apical interdigitations (Czolij et al., 1984), (Chapman and AbuEid, 2001). The epithelial cells of the proventriculus and mesenteric valve of the termite species under the present investigation exhibit abundant invaginations lead to the formation of intercellular channels. These channels are in direct contact with the basal lamina. Through these channels mostly an electron lucent and rarely an electron dense substances move into the epithelial cells through formation of vacuoles. These substances are presumably for nourishment of the epithelial cells as it is lined with thick intima. (Czolij et al., 1984) supposed that the interdigitations support the epithelial cells against rhythmically compressed peristalsis. This could be the same function of the apical cytoplasmic processes in the present study.

\section{Acknowledgment:-}

We would like to appreciate to the staff members of the electron microscope unite in faculty of Agriculture Research Park in Cairo University. 


\section{References:-}

1. Baker, J., Woo, S. and Byrd, R. (1984): Ultrastructural features of the gut of Sitophilus granarius (L.)(Coleoptera: Curculionidae) with notes on distribution of proteinases and amylases in crop and midgut. Can. j. zool, 62: 1251-1259.

2. Cakici, O. and Ergen, G. (2012): Light and scanning electron microscope investigations on the structure of proventriculus in Melanogryllus desertus (Pallas, 1771)(Orthoptera: Gryllidae). Turk. J. Entomol., 36(4): 541548.

3. Chapman, G. B. and Abu-Eid, C. (2001): The proventriculus of the carpenter bee, Xylocopa virginica virginica (L.), with special reference to bacteria-containing luminal tunnels. Inv. Biol., 120: 78-87.

4. Czolij, R., Slaytor, M., Vivers, P. C. and O'Brien, R. W. (1984): Gut morphology of Macrotermes darwininsis Froggatt (Isoptera: Mastotermitidae). Int. J. Insect Morphol. and Emberyol., 13: 337-355.

5. Darwish, A. (2007): Ultra structural study of proventriculus of female Culex pipiens and its role in blood digestion 17th conference of the Egyptian German Society of Zoolog. Dresden and Dusseldorf, Germany.

6. DuPorte, E. M. (1918): On the structure and function of the proventriculus of Gryllus pennsylvanicus Burm. Psyche, 25: 117-122.

7. Fontanetti, C. S. and Zefa, E. (2000): Morphological characterization of the proventriculus of Gryllus assimilis Fabricius (Orthoptera, Gryllidae). Revista Brasileira de Zoologia, 17: 193-198.

8. Fontanetti, C. S., Zefa, E., Passetti, F. and Mesa, A. (2002): Morphological characterization and comparative analysis of the proventriculus from three species of Endecous Saussure, (Orthoptera: Gryllidae: Phalangopsinae). Entomotropica, 17: 15-23.

9. Gullan, P. J. and Cranston, P. S. (2005): The gut, digestion and nutrition. In "The Insects, An outline of Entomology" Blackwell publishing, pp. 68-77.

10. Judd, W. W. (1948): A comparative study of the proventriculus of orthopteroid insects with reference to its use in taxonomy. Canadian journal of research, 26: 93-161.

11. Klowden, M. J. (2013): "Physiological systems in insects," $3^{\text {rd }}$ edition London Academic Press.

12. Krishnan, M. (1986): Scanning Electron Microscopic Studies of the Proventricular Armature of some Blattids (Insecta: Dictyoptera). Proc. Indian nam. Sci. Acad, 1152: 409-424.

13. Nation, S. J. L. (2016): Digestion. In "Insect Physiology and Biochemistry". . 3rd ed. CRC Press, pp. 33-65.

14. Noirot, C., and Noirot-Timothée, C. (1969): La cuticule proctodéale des Insectes. Zeitschrift für Zellforschung und Mikroskopische Anatomie, 101: 477-509.

15. Roche, R. K. and Wheeler, D. E. (1997): Morphological specializations of the digestive tract of Zacryptocerus rohweri (Hymenoptera: Formicidae). Journal of Morphology,234: 253-262.

16. Romoser, W. S. and Stoffolano, J. J. (1998): The alimentary system. In"The Science of Entomology". 4th ed. WCB, McGraw-Hill, pp. 88-100.

17. Serrão, J. E. (2001): A comparative study of the proventricular structure in corbiculate apinae (Hymenoptera, Apidae). Micron, 32: 379-385.

18. Serrão, J. E. (2005): Proventricular structure in solitary bees (Hymenoptera: Apoidea). Organisms Diversity \& Evolution, 5: 125-133.

19. Serrão, J. E. (2007): Proventricular structure in the bee tribe Augochlorini (Hymenoptera: Halictidae). Organisms Diversity \& Evolution, 7: 175-180.

20. Terra, W., Ferreira, C., Resh, V. and Cardé, R. (2003): Encyclopedia of insects. Digestive system, pp. 313-323.

21. Tokuda, G., Nakamura, T., Murakami, R. and Yamaoka, I. (2001): Morphology of the digestive system in the wood-feeding termite Nasutitermes takasagoensis (Shiraki)[Isoptera: Termitidae]. Zoological Science, 18: 869877.

22. Wang, Y., Su, Y., Zhang, X., Li, N. and Ren, B. (2012): A comparative study of the proventricular structure in twenty Chinese Tettigoniidae (Orthoptera) species. Entomologica Fennica, 23: 140-148. 